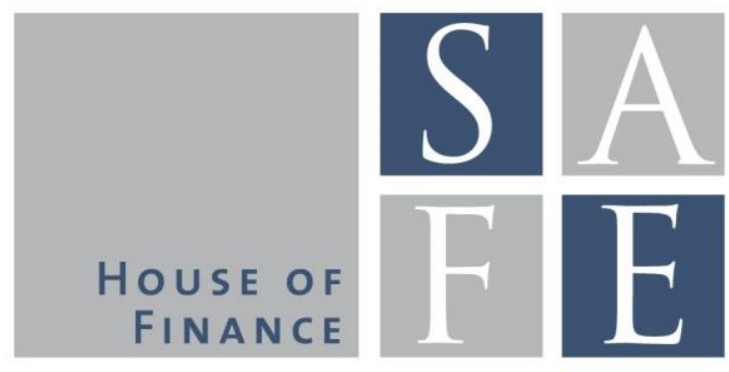

Working PAPER SERIES

Joost Driessen - Theo E. Nijman - Zorka Simon

\title{
The Missing Piece of the Puzzle: Liquidity Premiums in Inflation-Indexed Markets
}

SAFE Working Paper No. 183

SAFE I Sustainable Architecture for Finance in Europe A cooperation of the Center for Financial Studies and Goethe University Frankfurt 


\section{Non-Technical Summary}

Inflation-indexed products constitute a multitrillion dollar market segment worldwide. These assets can be found in many investment and hedging portfolios: the most common inflation payers are sovereigns, utility companies, and real estate investors; while on the receiver side pension and insurance funds, asset managers and investment banks are the most prominent counterparties. Despite their practical importance and the corresponding anecdotal evidence, studying liquidity characteristics of these assets has not attracted academic attention comparable to that of nominal bonds. Nevertheless, understanding these liquidity effects is important for several reasons. First, liquidity effects directly matter for the relative pricing of nominal and indexed bonds, as well as for the breakeven inflation rate implied by these prices. Similarly, liquidity effects in inflation swaps distort the inflation expectations that can be extracted from quoted swap prices.

We show that in both index-linked bond markets and inflation swap markets liquidity is an important determinant of prices. We do so by estimating a model with both a liquidity risk factor and asset-specific liquidity characteristics. To estimate the effect of liquidity risk, we measure an asset's exposure to a non-traded liquidity factor. In addition to this risk exposure, the level of liquidity is proxied by asset-level characteristics. We conduct our analyses based on two alternative assumptions - we either propose the three markets being segmented (benchmark case), such that prices are independently determined, or integrated markets. We find strong evidence that the level of liquidity affects yields of TIPS, whereas inflation swap yields include a liquidity risk premium. More specifically, for TIPS, the effect of illiquidity risk is dominated by that of asset characteristics. Age and size of an issue together carry a sizable premium of about 33 basis points per year. As for inflation swaps, we find that illiquidity risk is priced, yet the premium and the implied economic effect, 1.65 basis points per year, are small. We also study liquidity effects in nominal bonds in a similar way, and find a small liquidity risk premium in the nominal bond market, similar in magnitude to that of the on-the-run spread. In integrated markets, results regarding TIPS and nominal Treasuries are akin to the benchmark case, however, the price of illiquidity risk in the swap market is negative and twice as large as in the benchmark case, -3.41 basis points per year.

Additionally, we also study whether the exposure to liquidity and liquidity risk could explain the persistent difference in relative bond prices, as documented by Fleckenstein et al. (2014). They uncover a material price difference between nominal bonds and inflation-swapped indexed bonds (TIPS) that exactly replicate the cash flows of the nominal bond. This replicating portfolio trades at a discount relative to nominal bonds, which is mostly attributed to the underpricing of TIPS. But what could be the reason for this underpricing? To find the answer, we replicate their strategy and incorporate our estimated liquidity effects. We do so by adjusting the yields of nominal and indexed Treasuries by the estimated premiums of the benchmark case. We also include the effect of liquidity on inflation swap positions concerning every coupon payment within the strategy. We find 
evidence that when controlling for differences in liquidity premiums across the three markets, a substantial part of the puzzle disappears: after applying the liquidity correction based on segmentation (market integration), the average mispricing of $\$ 3.98$ shrinks to $\$ 1.17$ (\$2.47).

Our results are relevant for numerous market participants and for the government (Treasury). First, we show that both TIPS and inflation swap prices contain compensation for illiquidity. The latter also implies that the breakeven inflation rate is an imprecise proxy for inflation expectations and should only be interpreted keeping the potentially time-varying liquidity effects in mind. Second, by studying the TIPS-Treasury mispricing and showing that a large part thereof is due to liquidity premiums, we argue that the Treasury should keep issuing TIPS, since "there is no money left on the table". Moreover, TIPS have a large natural clientele: pension funds and insurers prefer to include these bonds in their asset portfolios to better hedge inflation risk of their long maturity liabilities, while investment banks and hedge funds often use TIPS in breakeven trades or hedging portfolios. 


\title{
The missing piece of the puzzle: Liquidity premiums in inflation-indexed markets
}

\author{
Joost Driessen ${ }^{1,3}$, Theo E. Nijman ${ }^{1,3}$, and Zorka Simon*2,3 \\ ${ }^{1}$ Tilburg University \\ ${ }^{2}$ Research Center SAFE - Goethe University Frankfurt \\ ${ }^{3}$ Netspar
}

September 2017

\begin{abstract}
Fleckenstein et al. (2014) document that nominal Treasuries trade at higher prices than inflation-swapped indexed bonds, which exactly replicate the nominal cash flows. We study whether this mispricing arises from liquidity premiums in inflation-indexed bonds (TIPS) and inflation swaps. Using US data, we show that the level of liquidity affects TIPS, whereas swap yields include a liquidity risk premium. We also allow for liquidity effects in nominal bonds. These results are based on a model with a systematic liquidity risk factor and asset-specific liquidity characteristics. We show that these liquidity (risk) premiums explain a substantial part of the TIPS underpricing.
\end{abstract}

Keywords: Liquidity premium, liquidity risk, TIPS, inflation swaps, TIPS-Treasury puzzle.

JEL classification:C51, G12, G01, H63.

*Email address of corresponding author: simon@safe.uni-frankfurt.de We would like to thank Dion Bongaerts, Frank de Jong, Alexander de Roode, Stefan Ruenzi and the seminar and conference participants of Tilburg Univeristy, Netspar Conference: Illiquid Investments and Robust Portfolio Choice, Netspar International Pension Workshop, and the Netspar Pension Day. Zorka Simon gratefully acknowledges research support from the Research Center SAFE, funded by the State of Hessen initiative for research LOEWE. 


\title{
The missing piece of the puzzle: Liquidity premiums in inflation-indexed markets
}

\author{
September 2017
}

\begin{abstract}
Fleckenstein et al. (2014) document that nominal Treasuries trade at higher prices than inflation-swapped indexed bonds, which exactly replicate the nominal cash flows. We study whether this mispricing arises from liquidity premiums in inflation-indexed bonds (TIPS) and inflation swaps. Using US data, we show that the level of liquidity affects TIPS, whereas swap yields include a liquidity risk premium. We also allow for liquidity effects in nominal bonds. These results are based on a model with a systematic liquidity risk factor and asset-specific liquidity characteristics. We show that these liquidity (risk) premiums explain a substantial part of the TIPS underpricing.
\end{abstract}

Keywords: Liquidity premium, liquidity risk, TIPS, inflation swaps.

JEL classification:C51, G12, G01, H63. 
Fleckenstein et al. (2014) document the TIPS-Treasury puzzle: they uncover a material price difference between nominal bonds and inflation-swapped indexed bonds (TIPS) that exactly replicate the cash flows of the nominal bond. This replicating portfolio trades at a discount relative to nominal bonds, which they attribute to the underpricing of TIPS. But what could be the reason for this underpricing? This paper aims to find the answer by performing a detailed study of liquidity effects in the inflation-indexed bond and inflation swap markets.

Inflation-indexed products constitute a multi-trillion dollar market segment worldwide. These assets can be found in many investment and hedging portfolios: Kerkhof (2005) explains that the most common inflation payers are sovereigns, utility companies, and real estate investors; while on the receiver side pension and insurance funds, asset managers and investment banks are the most prominent counterparties. Despite their practical importance and the corresponding anecdotal evidence, studying liquidity characteristics of these assets has not attracted academic attention comparable to that of nominal bonds. ${ }^{1}$ Nevertheless, understanding these liquidity effects is important for several reasons. First, liquidity effects directly matter for the relative pricing of nominal and indexed bonds, as well as for the breakeven inflation rate implied by these prices. Similarly, liquidity effects in inflation swaps distort the inflation expectations that can be extracted from quoted swap prices. Therefore, we assess whether part of the TIPS-Treasury puzzle is not mispricing but instead due to differences in liquidity premiums in the underlying asset markets.

Our paper has two key findings. First, we show that in both index-linked bond and inflation swap markets, liquidity is an important determinant of prices. We find strong evidence that the level of liquidity affects yields of TIPS, whereas inflation swap yields include a liquidity risk premium. These results are based on a model with a liquidity risk factor and asset-specific liquidity characteristics. We measure bond illiquidity by the ILLIQ measure of Amihud (2002), while swap illiquidity is proxied by the measure of Roll (1984). Our

\footnotetext{
${ }^{1}$ Several studies show that nominal bonds are very liquid, and thus exhibit only small liquidity premiums. See for instance Krishnamurthy (2002), Longstaff (2004), among many others.
} 
approach is inspired by Pastor and Stambaugh (2003) and Acharya and Pedersen (2005), as we measure the covariation of a security's return with market liquidity shocks. We estimate the effect of liquidity risk by means of a two-stage Fama-MacBeth procedure. In addition to this liquidity risk exposure, the level of liquidity is proxied by asset-level characteristics, such as the size or age of a bond issue, inspired by Krishnamurthy (2002) and Houweling et al. (2005). Additionally, we also study liquidity effects in the nominal bond segment in a similar way, so that in total we analyze liquidity premiums in three markets.

Conducting the analysis requires an assumption on whether, and to what extent the three market segments are integrated. This assumption directly affects the measurement of liquidity, especially the risk aspect thereof. Therefore, we present two alternatives - we either propose the three markets being segmented, such that prices are independently determined; or fully integrated markets. Due to its conservative nature, we choose the segmented model as our benchmark specification throughout the analysis. Then we find that for TIPS, the effect of illiquidity risk is dominated by that of asset characteristics. Age and size of an issue together carry a sizable premium of about 33 basis points per year. Following the interpretation of Houweling et al. (2005), this effect implies that the older the bond or the smaller the issue is, the yield of a TIPS issue tends to be higher. As for inflation swaps, we find that illiquidity risk is priced, yet the premium and the implied economic effect, 1.65 basis points per year, are small. Finally, we find a small liquidity risk premium in the nominal bond market, similar in magnitude to that of the on-the-run spread of Krishnamurthy (2002), but smaller than the premium estimated by Fontaine and Garcia (2012). These results are robust to the inclusion of various controls, and to estimation under the assumption of market integration. In integrated markets, results regarding TIPS and nominal Treasuries are akin to the benchmark case, however, the price of illiquidity risk in the swap market is negative and twice as large as in the benchmark case, -3.41 basis points per year.

The second contribution is that we link our results to the TIPS-Treasury puzzle of Flecken- 
stein et al. (2014). Their starting point is to match the maturities and payoffs of a nominal bond issue and its replicating portfolio. This synthetic 'nominal' bond is essentially a combination of a series of inflation swap contracts and a TIPS issue, whose cash flows are converted into fix payments, exactly matching those of the corresponding nominal bond. Fleckenstein et al. (2014) find that the replicating portfolio is persistently underpriced, and they attribute this to the underpricing of TIPS. To offer an alternative explanation, we replicate their strategy and incorporate our estimated liquidity effects. We do so by adjusting the yields of nominal and indexed Treasuries by the estimated premiums of the benchmark case. We also include the effect of liquidity on inflation swap positions concerning every coupon payment within the strategy. We find evidence that when controlling for differences in liquidity premiums across the three markets, a substantial part of the puzzle disappears: after applying the liquidity correction based on segmentation (market integration), the average mispricing of $\$ 3.98$ shrinks to $\$ 1.17(\$ 2.47)$.

The remainder of the paper is organized as follows. Section 1 discusses the related literature and our contributions, while Section 2 focuses on the theory, and the methodology. Next, Section 3 describes the data and the constituent asset markets. In Section 4 and Section 5, we present the empirical results of the market level analysis, and the effect of liquidity on the relative pricing of TIPS and Treasuries, respectively. Finally, Section 6 concludes.

\section{Related Literature}

By examining and quantifying the liquidity premium in the three markets, we contribute to the long-standing literature on the effect of liquidity on asset prices (Amihud and Mendelson (1986), Amihud (2002), Bekaert et al. (2007), and Bongaerts et al. (2011) among many others). More specifically, we follow the footsteps of Pastor and Stambaugh (2003) and Acharya and Pedersen (2005) to show that liquidity risk is priced, and provide novel evidence for 
Treasury bonds and inflation swaps. Moreover, we are also among the first ones to examine the effect of liquidity on inflation swaps, an important inflation derivative product. For instance, Chen et al. (2007), Bongaerts et al. (2011), and Tang and Yan (2007) study liquidity of other derivative markets, while to date, Kerkhof (2005), and Fleming and Krishnan (2012) have been the only papers examining the inflation swap market, but they do not estimate liquidity premiums.

By focusing on liquidity of TIPS, our paper also contributes to the literature on inflationindexed bond pricing. For instance, D'Amico et al. (2010), Gürkaynak et al. (2010), and Haubrich et al. (2012) propose term structure models, where they incorporate potential illiquidity of real bonds. Besides, Fleming (2003), Fleming and Sporn (2012), and Fleming and Krishnan (2012) present the microstructure characteristics of TIPS. Others like Campbell et al. (2009), Christensen and Gillan (2011), Pflueger and Viceira (2011, 2015), Fleckenstein et al. (2014), Fleckenstein (2013) and Simon (2015) specifically focus on the relative pricing of nominal and indexed Treasuries, and the breakeven rate, which is the yield difference between these two securities. Our study deepens the understanding of this matter by examining the effect of both the level and risk aspects of liquidity of TIPS. Moreover, we offer an empirical strategy that simultaneously examines the no-arbitrage relation between TIPS and nominal Treasuries, and the liquidity characteristics of constituent asset markets within the framework of a tradable strategy.

The approach of this paper is most closely related to Pflueger and Viceira (2015), Fleckenstein et al. (2014) and Simon (2015). Similarly to Pflueger and Viceira, we identify risk premiums and liquidity effects in bond yields. Unlike their paper, we do not incorporate time-varying behavior of risk premiums and return predictability in our analysis, as our primary objective is to quantify the effect of liquidity and liquidity risk on expected returns of TIPS, nominal Treasuries and inflation swaps. We also aim to answer to what extent the mispricing, found by Fleckenstein et al. (2014), is an artifact of liquidity premiums. We view our work as 
an extension of Fleckenstein et al. (2014) and Fleckenstein (2013), as we investigate the same no-arbitrage relationship between nominal and indexed Treasuries. Fleckenstein et al. (2014) provide evidence that part of this mispricing is caused by slow moving capital (see Gromb and Vayanos (2002), Mitchell et al. (2007), Brunnermeier and Pedersen (2009), Duffie (2010) and Ashcraft et al. (2010)), while we show that market liquidity premiums are also important to understand the price differences of indexed and nominal bonds. Simon (2015) complements our approach by studying differential sovereign risk in a cross-country sample of Eurozone nominal and inflation-linked bonds, and offers selective default risk premium in inflation-linked bonds as another piece to solve the TIPS-Treasury puzzle. We do not address this channel, as measuring selective default risk is non-trivial in a single country setting.

In conclusion, our work differs from the literature in the following aspects. First, unlike Pflueger and Viceira (2015) and Fleckenstein et al. (2014), we estimate the effect of liquidity based on a factor model that allows us to differentiate between liquidity premiums stemming from level and risk effects. Second, our primary liquidity proxy, the ILLIQ measure in Amihud (2002) does not rely on any implicit assumptions on the relative liquidity of nominal and indexed bonds, like in Pflueger and Viceira (2015) who assume nominal Treasuries to be perfectly liquid. In line with previous empirical evidence (Fontaine and Garcia (2012)), we allow nominal Treasuries to also carry compensation for liquidity risk. Third, we study the liquidity effects in inflation swap markets. Finally, we assess to what extent the price differential between indexed and nominal bonds can be explained by liquidity premiums. 


\section{Pricing of liquidity in the Treasury bond, TIPS and inflation swap markets}

In this section we explain our empirical strategy to examine the effects of liquidity and liquidity risk on prices in the three market segments. We base our empirical identification strategy on previous empirical findings: Amihud and Mendelson (1986) and Amihud (2002) show that average liquidity is priced in stock markets, both in the cross-section of stocks, as well as over time. Pastor and Stambaugh (2003) find that return sensitivity to market liquidity is priced, whereas Acharya and Pedersen (2005) present a model that disentangles three sources of liquidity risk - each being priced in the stock market.

We aim to test the following relationship between bond excess returns and liquidity:

$$
\mathbb{E}\left(R_{i, t}-R_{\mathrm{f}, t}\right)=\mathbb{E}\left(L i q_{i, t}\right)+\lambda_{\mathrm{LIQ}} \beta_{\mathrm{LIQ}, i}+\lambda_{\mathrm{MKT}} \beta_{\mathrm{MKT}, i}
$$

where $\mathbb{E}\left(L i q_{i, t}\right)$ is the unconditional expectation of the liquidity measure corresponding to

asset $i$ at time $t$, that aims to capture the level of liquidity of that asset. Furthermore $\beta_{\text {LIQ }, i}$ is the measure of an asset's exposure to marketwide illiquidity risk, proxied by a non-traded risk factor $\eta_{t}$. Likewise, $\beta_{\mathrm{MKT}, i}$ captures the covariance between returns of an asset and the market return. $\lambda_{\mathrm{LIQ}}$ and $\lambda_{\mathrm{MKT}}$ are the marketwide prices of exposure to liquidity and market risks, respectively.

We examine the above relation by estimating the two-step procedure defined in Equations 2 
and 3 in the time series of asset returns and in the cross-section of yields, respectively:

$$
\begin{array}{r}
R_{i, t}-R_{\mathrm{f}, t}=\alpha_{i}+\beta_{\mathrm{MKT}, i}\left(R_{\mathrm{MKT}, t}-R_{\mathrm{f}, t}\right)+\beta_{\mathrm{LIQ}, i} \eta_{t}+\varepsilon_{i, t} \\
\text { for } t=1,2, \ldots, T \text { for each } i \\
Y_{i, t}-Y_{f, t}=\gamma_{t}+\kappa_{t} L i q_{i, t}+\hat{\beta}_{\mathrm{MKT}, i} \lambda_{\mathrm{MKT}, t}+\hat{\beta}_{\mathrm{LIQ}, i} \lambda_{\mathrm{LIQ}, t}+\nu_{i, t}, \\
\text { for } i=1,2, \ldots, N \text { for each } t .
\end{array}
$$

The first time-series regression estimates how excess returns on an asset are driven by the market and liquidity factors. The second cross-sectional regression focuses on whether excess yields can be explained by the level of liquidity, as well as by exposure to the market and liquidity risk premiums. In Equation 3, we proxy expected returns by the yield-to maturity of the individual bonds or swap contracts. Below we discuss this further. Also note that the liquidity beta in our model corresponds to commonality in liquidity in the Pastor and Stambaugh (2003) sense, as it captures the covariance between individual asset return and the market-wide liquidity factor.

To estimate the relationship described by Equations 1- 3, we discuss the following five steps:

1. We calculate monthly asset and market returns for each asset in all three markets.

2. We define both asset and market level monthly liquidity proxies for each of the markets.

3. We construct a non-traded liquidity factor by taking the residual from an autoregressive (AR) time-series model of the liquidity measure.

4. We describe how we proxy expected returns.

5. We discuss the estimation strategy: how we test the above theoretical relationship by factor models that incorporate both the level and risk aspects of liquidity. 


\section{$2.1 \quad$ Asset and market returns}

For bond markets, one can apply the standard return definition based on the ratio of consecutive prices including a correction term when coupon payments occur. However, calculating returns of zero investment products, in our case inflation swaps, is nontrivial. We define returns on inflation swaps in accordance with bond market conventions, as the change in the swap rate from one period to the other, multiplied by the duration of the contract. We calculate duration as that of a bond, which has a coupon rate that equals the swap rate, and maturity of the swap contract. We multiply this product by minus one, to make the return definition resemble that of the bond convention.

$$
R_{\text {swap }, i, t}=-\left(r_{i, t}-r_{i, t-1}\right) \cdot \operatorname{Dur}_{\text {swap }, i, t}
$$

In addition to asset specific returns, we also construct market returns, as equally weighted average returns, where the average is taken over the cross-section of assets at a given point in time. This is similar to Amihud (2002), Chordia et al. (2001), and Acharya and Pedersen (2005). We use equal weighting since i) we do not have information on the traded amounts of the different swap contracts; ii) issuance amount-weighted bond returns are virtually identical to what we use.

\subsection{Liquidity proxies and additional controls}

For our empirical analysis, we need to measure liquidity. Keeping in mind the limited data availability in inflation swap markets, we capture swap liquidity by constructing measures that are directly derived from swap returns. Therefore, we propose the proportion of zero returns, and the Roll measures as liquidity proxies. Similarly to Bekaert et al. (2007), the proportion of zero returns over a given period is measured as the percentage of days with 
zero returns over a month. This measure is particularly useful for asset markets where data availability is limited. Our second swap liquidity proxy is based on Roll (1984). The Roll measure is derived from the autocovariance of returns, which captures the transitory component in observed prices. It is calculated as the scaled autocovariance for the case when it is strictly negative - otherwise the measure is truncated at zero. We interpret the Roll measure as the implied bid-ask spread. The key underlying assumption of this interpretation is that asset returns are identically and independently distributed over time.

$$
\operatorname{Roll}_{i, t}= \begin{cases}2 \sqrt{-\operatorname{cov}\left(R_{i, t}, R_{i, t-1}\right)}, & \text { if } \operatorname{cov}\left(R_{i, t}, R_{i, t-1}\right)<0 \\ 0, & \text { otherwise. }\end{cases}
$$

Measuring bond illiquidity also poses challenges, as many of the commonly applied measures, such as bid-ask spreads, are unreliable due to indicative quotes and lack of time variation. In addition, the proportion of zero returns or the Roll measure are uninformative over our sample period. This is because in the examined period all bonds are traded on a daily basis, thus the proportion of zero returns does not provide us with either cross-sectional or time series variation. For the Roll measure, the basic assumption of i.i.d. returns is not fulfilled, as bond returns exhibit positive autocorrelation for prolonged time periods. We therefore turn to certain asset characteristics that are linked to a security's liquidity. Houweling et al. (2005) propose issued amount and age of bond issues as such measures. For instance, age of a bond is an indirect liquidity proxy: the more time passes since issuance, the more likely that a bond gets locked-up in buy-and-hold investors' portfolios, which decreases its liquidity. This suggests a positive relationship between illiquidity and age, whereas issued amount is negatively related to the latter: larger issues tend to be more liquid. We define age as the years since issuance, and we use the natural logarithm of the issued amounts. In the spirit of Krishnamurthy (2002), we also include an indicator variable that equals 1 if the given issue is on-the-run - it is the latest issued security of its tenor - and zero otherwise. The publicly available issuance calendar suggests that TIPS are issued on an annual basis, whereas the 
cycle for nominal bonds is six months. Based on the idea that new issues are more liquid than previous ones, therefore carry smaller liquidity premium if at all, we expect the sign of this variable to be negative.

In addition to the previous liquidity proxies, we construct additional controls that we include in our analysis, such as yield volatility, or a control for the slope of term structure of bonds. Yield volatility is defined as the difference between the standard deviation of individual bond

yields and the cross-sectional average of the standard deviation of quoted yields, where the average is taken across the different maturities for a given month. This definition is the same for both swaps and bonds. A bonds yield volatility could also serve as a proxy for liquidity, since it functions as a measure of yield uncertainty. In case of more volatile yields, investors, especially market makers are uncertain of the bonds value, which increases bid-ask spreads and therefore leads to lower liquidity. On the other hand, volatility is likely to be correlated with potentially omitted factors in our models, thus we decided to include it in our regressions to partially alleviate any omitted variable bias. Nevertheless, the inclusion of yield volatility makes it more difficult for our liquidity effects to survive. We also include the time-to-maturity of each bond, measured in years at the two-decimal accuracy, to incorporate the slope effect of the term structure.

\subsection{The illiquidity factor}

To answer whether liquidity risk is priced, we turn to market-wide liquidity proxies. These measures are calculated on a monthly frequency. By means of the aggregate volume data on primary dealer transactions, accessed via the Federal Reserve Bank of New York, we construct the ILLIQ measure of Amihud (2002). The volume data cover information on primary dealer transactions and holdings that are reported weekly. We define the measure as a ratio of weekly absolute bond market returns over weekly aggregate trading volume, 
where the volume is aggregated across all dealers and all securities within their class. As most of our variables are at a monthly frequency, we smooth this variable by taking its average over the available observations in a given month.

We use the ILLIQ measure to construct separate illiquidity factors for nominal and indexed bonds in our benchmark analysis, but in the robustness checks we incorporate two alternative measures. In the first robustness check (BOND_PC), we take the first principal component of all ILLIQ measures corresponding to TIPS and all nominal Treasuries, therefore we construct an aggregate measure across the different markets. Our second alternative measure (ALL_PC) aims to capture a wider definition of liquidity and investor sentiment, by incorporating all bond ILLIQ measures, the TED spread, alongside with the VIX index and the average Roll measure across all swap maturities for a given month. For the swap market, our benchmark liquidity factor is simply the average Roll measure as defined previously, and as a robustness check we use the ALL_PC measure.

To examine the effect of liquidity on asset prices, we construct a factor that captures marketwide liquidity risk. In unreported regressions we show that our liquidity measures are persistent, thus we can define this risk as the surprise or unexpected liquidity, which is the difference between expected and realized liquidity. Thus for the aforementioned market-wide liquidity measures we define the liquidity risk factor the following way:

$$
\eta_{t}=L i q_{t}-\mathbb{E}_{t-1}\left[L i q_{t}\right]
$$

To compute these innovations, we impose an autoregressive structure for the liquidity measures, similarly to Acharya and Pedersen (2005).We determine the number of lags included by requiring the residual (unexpected) liquidity to behave as white noise. Consequently, we propose an $\mathrm{AR}(3)$ structure for the ILLIQ measure, and AR(1) for the average Roll measure, and for the principal components BOND_PC and ALL_PC used in the robustness analyses. ${ }^{2}$

\footnotetext{
${ }^{2}$ The underlying assumption of the factor construction is that the AR coefficients of the series in the
} 


\subsection{Measuring expected returns}

Our estimation strategy differs from the standard asset pricing approach in two aspects. First, we run our tests not on pre-sorted portfolios but on individual assets to be able to take advantage of the larger cross-sectional variation, similar to Ang et al. (2008). Second, in asset pricing tests, one usually proxies expected returns with average realized returns. However, because our sample period is short, returns are quite noisy, thus we turn to yields, which under some assumptions can be viewed as a forward-looking proxy for expected returns. This approach is similar to Pflueger and Viceira (2015), where they also look at yields to identify a liquidity premium in TIPS prices.

As is well known, the yield to maturity reflects the expected return when holding the bond to maturity. To use yields for expected returns over shorter horizons, we need to make additional assumptions. In general, we have to assume that the term structure of expected returns is flat for all assets. A sufficient condition for this is that the term structures of nominal yields, real yields and inflation expectations are all flat.

\subsection{Estimation strategy}

In this section we study how liquidity can affect expected returns. For that, we estimate the market-wide premiums on market and liquidity factors, as well as on our liquidity level proxies.

In light of existing evidence on the pricing of liquidity in sovereign bond markets (Krishnamurthy (2002), Goyenko et al. (2011), Fleckenstein et al. (2014), and Pflueger and Viceira

principal components are identical, or at least very similar. In the baseline specifications this assumption is met: the ILLIQ measures exhibit very similar time-series patterns and their AR coefficients are also quite similar: 0.58 and 0.62 for nominal Treasuries and TIPS, respectively. For swaps, we impose the AR structure on the Roll measure directly, therefore for the benchmark specification of each market segment, the above assumption holds. 
(2015) among many others), the purpose of this section is to show whether liquidity risk carries a premium in Treasury bonds and TIPS, in addition to inflation swaps. So far, no empirical evidence has been published on the liquidity in the spectrum of various inflation swap maturities, despite the anecdotal evidence on the market not being perfectly liquid at all times (Fleming and Sporn (2012)).

We approach the above question by following a two-stage Fama-MacBeth procedure. We estimate betas and risk loadings in each market separately. We measure the covariation of a security's return with that of the market and market liquidity. In the first stage we run the following time series OLS regressions to obtain the betas:

$$
\begin{array}{r}
R_{i, t}-R_{\mathrm{f}, t}=\alpha_{i}+\beta_{\mathrm{MKT}, i}\left(R_{\mathrm{MKT}, t}-R_{\mathrm{f}, t}\right)+\beta_{\mathrm{LIQ}, i} \eta_{t}+\varepsilon_{i, t} \\
\text { for } t=1,2, \ldots, T \text { for each } i ;
\end{array}
$$

where we include excess market returns and unexpected liquidity, which is the residual from the AR process discussed above. In the second stage we run repeated cross-sectional regressions of yields on the betas estimated in the previous step, asset level liquidity proxies and additional controls. Estimates from the repeated regressions are averaged across time and the standard errors for this average are calculated using a 12-lag Newey-West correction: ${ }^{3}$

$$
\begin{array}{r}
Y_{i, t}-Y_{\mathrm{f}, t}=\gamma_{t}+\kappa_{t} L i q_{i, t}+\hat{\beta}_{\mathrm{MKT}, i} \lambda_{\mathrm{MKT}, t}+\hat{\beta}_{\mathrm{LIQ}, i} \lambda_{\mathrm{LIQ}, t}+\nu_{i, t} \\
\text { for } i=1,2, \ldots, N \text { for each } t .
\end{array}
$$

As a result, we get estimates of the market price of liquidity and liquidity risk, as well as each asset's individual exposure to this risk. These models can be formulated based on two opposing assumptions: either we assume that the three markets are perfectly segmented and all forms of liquidity are priced separately; or we price liquidity risk in fully integrated

\footnotetext{
${ }^{3}$ For the exact formula see pp. 229 in Cochrane (2005).
} 
markets. The difference between the two approaches also affects the definition of the market (return). In the integrated case, the market return and liquidity factors are the equally weighted averages of all assets in positive net supply: nominal and indexed bonds. On the other hand, assuming segmentation produces separate market and liquidity factors for each segment. In this case, within each segment the average of market betas is one, while that of liquidity betas are zero by construction. As opposed to this, in the integrated case, these adding-up constraints only apply to the entire set of nominal and indexed bonds. We thus choose the more conservative segmented method for our benchmark specification, since liquidity risk premiums are likely smaller in this case.

\section{The data and the three markets}

In this section, we describe the data and the markets of nominal and indexed Treasuries and inflation swaps, focusing on potential liquidity issues.

\subsection{Constituent asset markets}

In this section we provide a short description of the TIPS and inflation swap markets, specifically focusing on market features that could lead to illiquidity. We also contrast the liquidity features of the three markets based on prior empirical work.

\subsubsection{The TIPS market}

The first TIPS auction took place in 1997, and ever since the market gradually grew into one of the largest and most-actively traded fixed income markets in the world (Fleckenstein et al., 2014). As of the end of our sample period, 41 individual TIPS issues have been auctioned 
on a regular cycle, with five-year, 10-year and 30-year maturities. ${ }^{4}$

TIPS, in most respects, are similar to nominal Treasuries, the main difference is that the principal amount is adjusted on a daily basis to changes in CPI to All Urban Consumers, the non-seasonally adjusted inflation rate in the US. The adjustment implies that semiannual coupons, that are a fixed percentage of the principal linked to changes in inflation, also vary over time. Another important feature of TIPS is the embedded deflation option, which protects investors from losses: in any case investors are entitled to the maximum of the final principal amount or its inflation-adjusted counterpart.

\subsubsection{The inflation swap market}

Kerkhof (2005) reports that the US zero-coupon inflation swap market has been a rapidly growing segment of the inflation derivatives market in the past decade, as market participants began making markets to hedge their inflation risk exposures. However, the current size of the market is still about a couple of percent that of nominal interest rate swaps, and is atomic compared to Treasury securities. In line with this, Fleming and Krishnan (2012) report that there are relatively few trades occurring in this market.

An inflation swap is a bilateral derivative transaction in which one party agrees to swap a fixed payment to a floating one that is tied to inflation, for a given notional amount and period of time. Inflation swaps, similarly to TIPS, are also linked to CPI-U, and the fixed rate is negotiated in over-the-counter transactions that are traded in a dealer-based market (Fleming and Krishnan (2012)). The most frequently traded inflation swap contracts are the zero coupon contracts, in which cash flows are only exchanged at the maturity of the contract.

So far, only a handful of studies investigated the breakeven rate, or its relationship with

\footnotetext{
${ }^{4}$ Previously TIPS with 20-year maturities were also issued by the Treasury.
} 
inflation swaps (Campbell et al., 2009; Gürkaynak et al., 2010; Christensen and Gillan, 2011; Pflueger and Viceira, 2015; Fleckenstein et al., 2014), but as Fleming and Krishnan (2012) point out, empirical evidence on inflation swap liquidity is still lacking. To date we are not aware of studies modeling the liquidity features of this market. Despite that the size of the market and the infrequency of trades would suggest that liquidity is likely to have an effect on swap returns, we cannot predict its expected direction. Bongaerts et al. (2011) theoretically show that a battery of factors, such as non-traded risk exposures in investors' portfolios, individual risk aversion, and liquidity's correlation with investors' hedging demands, determines the sign of the liquidity premium for markets that are in zero net supply (such as derivative markets). Since these factors are unobservable, especially at the aggregate level, we cannot predict the expected sign of liquidity premiums.

\subsubsection{The nominal Treasury market and liquidity}

The US nominal Treasury bond market is among the most liquid and most frequently traded fixed-income markets in the world, thus it is often taken as a reference point in investigating other securities' liquidity. Krishnamurthy (2002) uses the commercial paper-T-bill spread to capture changes in liquidity demand, whereas Longstaff (2004) applies the Refcorp-Treasury spread to capture a flight-to-liquidity premium in economically distressed times. Pflueger and Viceira (2015) treat nominal Treasuries as perfectly liquid to quantify the premium inherent in TIPS returns, and determine bond return predictability.

On the other hand, Krishnamurthy (2002) has shown that the liquidity of nominal bonds does vary significantly over the issuance cycle, therefore a liquidity premium could arise in Treasury returns too. For this reason, we also take a look at the liquidity of these bonds.

Note that although our sample contains all available TIPS that are issued prior to December 30, 2011, it could contain significantly more nominal issues. This is because the data has 
been collected in the spirit of Fleckenstein et al. (2014), such that it comprises of maturitymatched indexed and nominal bond pairs. Still, our nominal bond sample exhibits sufficient variation in liquidity features such that our results can likely be generalized to the entire population of long-maturity nominal Treasuries.

\subsection{The data}

The data consist of daily closing midquote prices of TIPS, nominal Treasury bonds and zero coupon inflation swaps. These data are obtained from Bloomberg, and are an extended and updated version of Fleckenstein et al. (2014) - we include a larger cross-section of existing TIPS issues with a matched subset of the long-term nominal Treasury market with a longer time span. Our bond sample consists of maturity-matched indexed and nominal issues, with maturities ranging between 2007 and 2041. ${ }^{5}$ The daily closing bond prices are adjusted by accrued interest following the market convention.

We also collect data on inflation swap quotes, which are the fixed rates on the fixed leg of an inflation swap. Following Fleckenstein et al. (2014), we choose contracts with maturities ranging between 1 to 10, 12, 15, 20, 25 and 30 years. We apply the simplest approach to get intermediate (non-traded) maturities: we use a linear interpolation technique and include no correction for potential seasonal patterns in inflation. We collect data for the US market from July 2004 to December 2011.

To investigate the effect of liquidity, we also gathered information on the bonds' issue and maturity dates, the issue size and coupon rates. To formally test whether liquidity risk is priced, we download additional controls from Bloomberg, such as the TED spread, the VIX index - next to deriving measures from prices themselves. To construct our benchmark

\footnotetext{
${ }^{5}$ The original sample consists of 41 TIPS and 40 maturity-matched nominal issues. However, for the asset pricing test we applied two data filters: we omitted issues from the sample that had less than 24 months of data and kept observations up to six months before a bond's maturity.
} 
liquidity proxy, we accessed the Primary Dealer Historical Search database of the Federal Reserve Bank of New York, where they provide information on primary dealer transactions and holdings that are reported on a weekly frequency. The published figures are aggregated over all primary dealers, for a given security class and week. Finally, we also obtain 1-month risk free rates from Kenneth French's website and risk free yields from St. Louis Fed's FRED database.

\section{Empirical results}

This section presents the result of the two-stage model described in Section I. We first discuss the descriptives, and the beta estimates from Equation 7, alongside with the properties of the liquidity factor. We proceed with discussing the benchmark results for all three markets. Next, we also provide robustness tests to the inclusion of other liquidity measures, and alternative assumption (integrated markets).

\subsection{Descriptives, betas and the illiquidity factor}

Table 1 contains the descriptive statistics of our liquidity proxies for all three markets in our

sample, whereas Table 2 provides the distribution of the betas estimated in the first stage of our analysis. Table 1 reports all quantities, except for the ILLIQ measure and the on-the-run dummy, in percentages; and shows the distribution of our liquidity measures.

In the swap market, the average yield is $2.47 \%$. The relative yield volatility measure by construction equals to zero, but individual issues can significantly differ from the crosssectional average. The Roll measure implies an average bid-ask spread of 24.5 basis points. On average, $5.82 \%$ of the times we have zero returns on this market, which suggests no trading activity on average 1.8 days a month. 
The average TIPS yield is 74 basis points and yield volatility of individual issues varies in a wider range than for swaps. The age of the average indexed bond in our sample is 4.38 years with average time to maturity of 9.12 years. The average issue size for indexed bonds is $\$ 16.1$ billion. The dummy variable shows that $12.67 \%$ of the issues are on-the-run. We also present ILLIQ, a price impact proxy measured as the absolute dollar change triggered by the traded volume (scaled by $\$ 1$ million).

In comparison, nominal Treasuries have higher yields, on average $1.58 \%$, with lower relative yield volatility than TIPS or inflation swaps. These bonds are older, with the average age of 5.86 years, with also somewhat longer time to maturity, 9.48 years. The average nominal issue is also larger than that of TIPS, with $\$ 21$ billion. Only $4 \%$ of the issues are on the run, which is mechanically smaller than the figure of TIPS since nominal bonds are issued twice as frequently as TIPS.

Figure 1 depicts the time evolution of our liquidity factors, defined as the residual from autoregressive processes: AR(3) for ILLIQ measures of TIPS, and AR(1) for the nominal Treasury ILLIQ and the average Roll measures. The TIPS and nominal bond series are relatively highly correlated, with a correlation coefficient of 0.61 , whereas their correlation with the inflation swap market series is 0.17 and 0.41 , respectively. Apparently, the TIPS liquidity factor has larger swings and more spikes than the other two series, with all factors shooting up during the recent financial crisis.

After applying the data filters, we estimate market and liquidity betas for 15 swap, 31 TIPS and 32 nominal bonds. As such, given the large number of individual assets, Table 2 focuses on the distribution of betas that we estimate from time-series regressions ${ }^{6}$ of returns on the market excess return and the illiquidity factor. Note that our market factor in this context is practically an interest rate risk or duration factor, which explains the patters in

\footnotetext{
${ }^{6}$ We conclude from unreported results that market betas are highly significant in case of most assets, whereas the statistical significance of individual liquidity betas varies substantially.
} 
Figures 2- 4. These graphs depict the betas sorted on average age of an issue for TIPS and nominal Treasuries, and contract maturity for inflation swaps. We present result under both integrated and segmented market assumptions. In segmented markets, the average of market betas is one, whereas that of liquidity betas is zero by construction within each segment.

In the inflation swap market, assuming segmentation, we see that liquidity betas have a larger spread than market betas. Loadings on the market factor are all positive. In the integrated case, where we take market as the sum of the nominal and indexed bonds, our estimates change: the average market beta is still close to zero, however certain issues load on the market factor with a negative sign. We also see that the magnitude and the spread of liquidity betas substantially increase, while they always have a negative sign. The two panels of Figure 2 confirm these findings.

Figures 3 and 4 expose that in both the segmented and integrated cases, TIPS and nominal bonds have strictly positive market betas, which vary in a narrower range than those of swaps. We observe a similar difference in range for segmented liquidity betas of TIPS. Ex ante, we would expect TIPS prices to decrease if liquidity decreases. In contrast, when we assume markets are integrated, most TIPS issues load positively on our illiquidity factor, whereas nominal bonds tend to have negative and sizable illiquidity betas.

\subsection{Benchmark results}

We estimate our benchmark models (i) under the assumption of market segmentation; (ii) using illiquidity factors derived from ILLIQ for bonds and the average Roll measure for inflation swaps; (iii) for the period between July 2004 and December 2011. To define the baseline specification, we pick models that explain the data well, yet are parsimonious. Consequently, for nominal Treasuries and inflation swaps, we pick the model with the market and illiquidity factors as our baseline specifications, whereas for TIPS, based on unreported univariate re- 
gressions, we extend the latter model with two characteristics: age and size of a TIPS issue. To capture the economic effect of risk premiums, we define the interquartile spread as the estimated price of risk multiplied by the difference between the betas corresponding to the first and third quartile in the cross-section of betas. Parameter estimates of the benchmark cases can be found in the first columns of Tables 3, 5, and 7 .

The first column of Table 3 presents the benchmark model for inflation swaps. Despite the lack of prior literature on inflation swap liquidity, anecdotal evidence of Fleming and Krishnan (2012) suggest the existence of liquidity premium in swap rates. Nevertheless, we cannot predict its expected direction, as there are many factors that determine how liquidity impacts markets that are in zero net supply, as shown by Bongaerts et al. (2011). The key empirical result for inflation swaps is that both market and liquidity risks are priced. The market price of liquidity risk is positive, and it is statistically significant, nevertheless the implied economic impact is small: 1.65 basis points per year. On the other hand, the economic impact of systematic market risk is a sizable 43.92 basis points per year.

Table 5 reports our benchmark case for TIPS. The growing literature on TIPS illiquidity suggests TIPS prices to convey a liquidity discount. ${ }^{7}$ Therefore, we expect liquidity risk to be priced. As for the included characteristics, for age we expect a positive sign, while larger bond issued tend to be more liquid, therefore the expected sign of size is negative. Our main finding is that for TIPS, the effect of illiquidity risk is dominated by asset characteristics. While market risk is priced, illiquidity risk is both statistically and economically insignificant. As opposed to this, age seems to be both statistically and economically an important driver of TIPS liquidity. If a bond gets one year older, its yield will increase with 9.09 basis points. Moreover, the size of an issue also matters: an increase in TIPS amount issued of $1 \%$ corresponds to a decrease in yield of 0.31 basis points.

\footnotetext{
${ }^{7}$ Including Campbell et al. (2009), Christensen and Gillan (2011), Pflueger and Viceira (2011, 2015), Haubrich et al. (2012), Fleckenstein et al. (2014)
} 
Results of nominal Treasury notes and bonds can be found in Table 7 . In line with previous literature, we find that nominal bonds are more liquid than other securities - as in Krishnamurthy (2002), Longstaff (2004) or Pflueger and Viceira (2015), among many others. Our benchmark specification focuses on the two factors: market and illiquidity. Ex ante, the sign of the illiquidity premium is not clear, as for instance Fontaine and Garcia (2012) find negative liquidity premium in nominal Treasuries, which makes these securities a good liquidity hedge in periods of flight-to-liquidity. We find that in the nominal Treasury market illiquidity risk is priced, and carries a positive but fairly small premium of 13.13 basis points. At the same time, the economic effect of the market risk (interest rate risk) is substantial, with 183.22 basis points.

\subsection{Robustness tests}

To check the robustness of our benchmark specifications, we include additional controls, as well as test the effect of the assumption of integration. In unreported results we also construct and assess other liquidity factors, alongside with splitting our period into subsamples. We also test whether the price of liquidity risk is different in different liquidity regimes: when we restrict our sample to those months when our aggregate market illiquidity factor increases, and separately to those when it increases.

Taking another look at Table 3, we find that the benchmark case for inflation swaps is robust to the inclusion of asset characteristics and controls, such as the proportion of zero returns, or the volatility of swap yields. In all cases, the economic impacts of market and liquidity risk exposures do not change substantially either in sign or magnitude. In contrast, we also perform a similar analysis under the assumption of swap and bond market integration. Table 4 shows that both the market and illiquidity betas are priced. These effects are also highly significant and robust to the inclusion of volatility. In this integrated case where 
illiquidity risk captures illiquidity across all markets, the coefficient of illiquidity risk is negative, which is the usual sign for such systematic liquidity risk: illiquidity betas are usually negative (low returns when illiquidity increases), and hence a negative price of risk is needed to obtain a positive illiquidity risk premium. For inflation swaps, illiquidity betas are indeed negative (Table 2), which implies a positive illiquidity risk premium in inflation swap rates. The implied premium is substantial: it is between 18.2 and 34.1 basis points.

For TIPS, we observe that age and the size of an issue matter more than liquidity risk. Other columns in Table 5 show accordingly. However, if we only include the market and the illiquidity factor, in Column 2, liquidity risk seems to carry a significant and sizable premium of -22.6 basis points, and this remains so after the inclusion of the on-the-run dummy, issued amount and yield volatility. Nevertheless, once age or time-to-maturity are included, these variables wipe out the factor's significance. Similarly to swaps, we repeat the analysis for integrated markets and results can be found in Table 6. In general, results do not change: the magnitude of the effects is both statistically and economically similar to the previous case. Therefore, we conclude this market is not as sensitive to the assumption on the extent of integration as that of inflation swaps.

Looking at nominal Treasuries, we show that the market and illiquidity premiums are robust to the inclusion of asset level characteristics and controls. Interestingly, age next to being significant in all specifications, has the wrong sign. We suspect that age might have a nonlinear relationship with yields. The coefficient on the time-to-maturity control suggests that the slope of the term structure matters; besides other variables, such as the on-therun dummy, issued amount and yield volatility, are never significant. In comparison, if we take the integrated market case in Table 8, the characteristics and controls seem to carry a more important role. The market and illiquidity factors are highly significant with similar premiums estimates as under the market segmentation assumption. Age still has the wrong sign, but now the size and yield volatility of an issue are significant determinants of yields. 
In Table 9, we present results conditional on whether market liquidity is increasing or decreasing. To do so, we pool together months where changes of market liquidity are either positive or negative, respectively. What we find is that in all three market segments both the signs, as well as the magnitudes of the estimated risk premia are stable across liquidity regimes. This suggests that our results are robust to liquidity regimes.

\section{The relative pricing of TIPS and nominal Treasuries}

In this section, we use the results of the previous section to examine the effect of liquidity on the relative pricing of nominal and indexed Treasuries, following Fleckenstein et al. (2014). ${ }^{8}$ The idea behind their TIPS-Treasury arbitrage is simple: an investor matches the maturities and payoffs of a nominal bond issue and its synthetic counterpart. The latter is essentially an inflation swapped-indexed bond, whose cash flows are converted to fix payments exactly matching that of the corresponding nominal bond.

The arbitrage strategy is as follows. An investor should buy a TIPS issue and short a nominal bond at the same time. Additionally, she needs to execute a zero-coupon inflation swap contract with the same maturity and notional amount as the TIPS coupon - and repeat this for each coupon and for the principal amount, which results in the execution of an entire swap portfolio. The rationale for swapping the indexed bond is that the sum of the two cash flows is constant and equal to the nominal coupon or principal. The investor also needs to take a small position in Treasury STRIPS due to the disparity in the nominal and TIPS coupon payments. ${ }^{9}$ Based on this logic, the investor applies these steps to all coupon

\footnotetext{
${ }^{8} \mathrm{~A}$ minor difference in comparison to Fleckenstein et al. (2014) is that we base our mispricing calculations on clean prices. We use clean prices to circumvent that due to the coupon dates of many bonds in the crosssection coinciding, we observe a jagged pattern in the average mispricing series that arises due to the average accrued interest. To circumvent this problem, we decided to use clean prices.

${ }^{9}$ We are aware that STRIPS might also be exposed to liquidity issues (see for instance Daves and Ehrhardt (1993) or Jordan et al. (2000)), however Bühler and Vonhoff (2011) find that principal STRIPS are less affected. As the trading strategy presented in this paper uses principal STRIPS, we are less concerned that
} 
payments, which results in the successful conversion of the TIPS variable cash flow stream to the fixed one of the corresponding nominal bond.

To calculate what Fleckenstein et al. (2014) call mispricing, we first calculate the cash flows of the synthetic bond, from which we can derive the price of the replicating portfolio. In this pricing exercise we also take care of any potential maturity mismatch between the nominal bond and the TIPS. Finally, to get the price differential, we take the difference between the price of the nominal bond and its replicating portfolio - theoretically, any difference indicates a potential arbitrage opportunity.

To incorporate the direct effect of liquidity, we adjust the yields of nominal and indexed Treasuries by the estimated premiums of the benchmark cases. We also include the effect of liquidity on inflation swap positions, concerning every coupon payment within the strategy. To take account of the liquidity-adjustment in swap contracts, we calculate the difference of the fixed leg, with and without liquidity adjustment:

$$
\text { Value }_{\mathrm{swap}, t}=\frac{s\left(1+y_{\mathrm{swap}, n, t}-\hat{\beta}_{\mathrm{LIQ}, \mathrm{swap}} \lambda_{\mathrm{LIQ}}\right)^{n}}{\left(1+y_{\mathrm{zc}, n, t}\right)^{n}}-\frac{s\left(1+y_{\mathrm{swap}, n, t}\right)^{n}}{\left(1+y_{\mathrm{zc}, n, t}\right)^{n}} .
$$

where $y_{\mathrm{swap}, n, t}$ is the quoted swap yield of an n-maturity contract at time $t$, whereas $y_{\mathrm{zc}, n, t}$ is the nominal zero-coupon yield of the same maturity at the same point in time. Before the liquidity adjustment, the value of the swap position is zero. However this changes as we incorporate the correction: the value of the liquidity adjusted position is the liquiditycorrected value of the fixed leg, minus the unadjusted value of the fixed leg. The value of the floating leg obviously remains unchanged. Given that the replicating strategy has inflation swaps such that one receives the fixed payment and pays the floating payment, the liquidity adjustment is negative if $\hat{\beta}_{\mathrm{LIQ}, \text { swap }} \lambda_{\mathrm{LIQ}}^{n}>0$. In this case part of the fixed inflation swap rate small positions taken in these assets would carry a sizable liquidity premium that could distort our results. 
is compensation for illiquidity, and removing this liquidity premium leads to a lower fixed rate and hence lower value for the investor. Hence, if $\hat{\beta}_{\mathrm{LIQ}, \text { swap }} \lambda_{\mathrm{LIQ}}^{n}>0$, which is what we find in the case of integration, the puzzle is deepened by the liquidity premium in inflation swap markets. For non-traded or fractional maturities, we apply linear interpolation to get the forward rate, as well as the size of the liquidity premium.

The result of the liquidity correction can be found in Figure 5 and Table 10. Figure 5 compares the replicated 'mispricing' of Fleckenstein et al. (2014)), and its adjusted counterparts under the assumptions of segmented and integrated markets. Our key result is that once we take out the estimated liquidity premiums from prices, the price differential shrinks considerably. This is in accordance with our hypothesis that a large part of the mispricing arises due to the difference of liquidity premiums locked in by the trading strategy. The shrinkage of the price difference persist under both specifications, although the effect of our liquidity adjustment is larger for segmented markets. Table 10 confirms these findings: whereas all arbitrage profits without liquidity correction are positive, the adjusted series based on both corrections can take negative values, suggesting a non-trivial liquidity premium in TIPS and swaps prices. We also define the difference between the mispricing series, as the difference between the original strategy and the liquidity adjusted series. We find that this disparity is always positive and often times considerable in magnitude, especially in proportion to the unadjusted series. However, we do see that our constant liquidity adjustment performs best outside the financial crisis, where other forces, such as flight-to-safety, could pay a role in the relative pricing of nominal Treasuries and TIPS. 


\section{Conclusion}

We show that in both index-linked bond markets and inflation swap markets liquidity is an important determinant of prices. We do so by estimating a model with both a liquidity risk factor and asset-specific liquidity characteristics. To estimate the effect of liquidity risk, we measure an asset's exposure to a non-traded liquidity factor. In addition to the liquidity risk exposure, the level of liquidity is proxied by asset-level characteristics. We also study liquidity effects in nominal bonds in a similar way, so that in total we analyze liquidity premiums in three markets. We conduct our analyses based on two alternative assumptions - we either propose the three markets being segmented, such that prices are independently determined, or integrated markets.

Additionally, we also study whether the exposure to liquidity and liquidity risk could explain the persistent difference in relative bond prices, as documented by Fleckenstein et al. (2014). They show that there exist a substantial price differences between a nominal Treasury bond and its synthetic counterpart - a swapped TIPS issue. We provide evidence that when controlling for liquidity, a large part of this apparent mispricing can be explained, especially outside the financial crisis.

Yet, several extensions of the paper are possible and considered. An important question to be addressed is whether the liquidity proxies are affected by unconventional monetary policy actions, like quantitative easing during the crisis, as studied by Christensen and Gillan (2013) or D'Amico and King (2013). Some other issues also remain to be solved, such as examining the robustness of our results to the construction of liquidity factors, or introducing time variation in the estimation of risk exposures or risk premiums. 


\section{References}

Acharya, V. and Pedersen, L. H. (2005). Asset Pricing with Liquidity Risk. Journal of Financial Economics, 77 (2): 375-410.

Amihud, Y. (2002). Illiquidity and Stock Returns: Cross-Section and Time-Series Effects. Journal of Financial Markets, 5 (1): 31-56.

Amihud, Y. and Mendelson, H. (1986). Asset Pricing and the Bid-Ask Spread. Journal of Financial Economics, 17 (2): 223-249.

Ang, A., Liu, J., and Schwarz, K. (2008). Using Stocks or Portfolios in Tests of Factor Models. Working paper, Columbia University.

Ashcraft, A., Gârleanu, N., and Pedersen, L. H. (2010). Two Monetary Tools: Interest Rates and Haircuts. Working paper, New York University.

Bekaert, G., Harvey, C. R., and Lundblad, C. (2007). Liquidity and Expected Returns: Lessons from Emerging Markets. Review of Financial Studies, 20 (6): 1783-1831.

Bongaerts, D., De Jong, F., and Driessen, J. (2011). Derivative Pricing with Liquidity Risk: Theory and Evidence from the Credit Default Swap Market. Journal of Finance, 66 (1): $202-240$.

Brunnermeier, M. and Pedersen, L. H. (2009). Market Liquidity and Funding Liquidity. Review of Financial Studies, 22 (6): 2201-2238.

Bühler, W. and Vonhoff, V. (2011). Term Structures of Liquidity Premia in the U.S. Treasury Market. Working paper.

Buraschi, A. and Jitsov, A. (2005). Inflation Risk Premia and the Expectation Hypothesis. Journal of Financial Economics, 75 (2): 429-490.

Campbell, J. Y., Shiller, R. J., and Viceira, L. M. (2009). Understanding Inflation-Linked Bond Markets. In Romer, D. and Wolfers, J., editors, Brookings Papers on Economic Activity, 79-120. Brookings Institution Press.

Chen, L., Lesmond, D. A., and Wei, J. (2007). Corporate Yield Spreads and Bond Liquidity. Journal of Finance, 62 (1): 119-149.

Chordia, T., Roll, R., and Subrahmanyam, A. (2001). Market Liquidity and Trading Activity. Journal of Finance, 56 (2): 501-530.

Christensen, J. H. and Gillan, J. M. (2011). Has the Treasury Benefited from Issuing TIPS? Federal Reserve Bank of San Francisco Economic Letters.

Christensen, J. H. E. and Gillan, J. M. (2013). Does Quantitative Easing Affect Market Liquidity? Working paper 2013-26, Federal Reserve Bank of San Francisco. 
Cochrane, J. H. (2005). Asset Pricing. Princeton University Press, New Jersey, New Jersey, revised edition.

Cochrane, J. H. and Piazzesi, M. (2002). The Fed and Interest Rates: A High-Frequency Identification. American Economic Review PESP, 92 (2): 90-95.

Cochrane, J. H. and Piazzesi, M. (2005). Bond Risk Premia. American Economic Review, 95 (1): 138-160.

D'Amico, S., Kim, D. H., and Wei, M. (2010). Tips from TIPS: The Informational Content of Treasury In?ation-Protected Security Prices. Finance and Economics Discussion Series 2010-19, Federal Reserve Board.

D'Amico, S. and King, T. B. (2013). The Flow and Stock Effects of Large-Scale Treasury Purchases: Evidence on the Importance of Local Supply. Journal of Financial Economics, 108 (2): $275-564$.

Daves, P. R. and Ehrhardt, M. C. (1993). Liquidity, Reconstitution, and Value of U.S. Treasury Strips. Journal of Finance, 48 (1): 315-329.

Duffie, D. (2010). Asset Price Dynamics with Slow-Moving Capital. Journal of Finance, 65 (4): 1238-1268.

Fleckenstein, M. (2013). The Inflation-Indexed Bond Puzzle. Working paper.

Fleckenstein, M., Longstaff, F. A., and Lustig, H. (2014). The TIPS-Treasury Bond Puzzle. Journal of Finance, 69 (5): 2151-2197.

Fleming, M. and Sporn, J. (2012). An Analysis of OTC Interest Rate Derivatives Transactions: Implications for Public Reporting. Staff report 557, Federal Reserve Bank of New York.

Fleming, M. J. (2003). Measuring Treasury Market Liquidity. Federal Reserve Bank of New York Economic Policy Review, 83-108.

Fleming, M. J. and Krishnan, N. (2012). The Microstructure of the TIPS Market. Federal Reserve Bank of New York Economic Policy Review, 27-45.

Fontaine, J.-S. and Garcia, R. (2012). Bond Liquidity Premia. Review of Financial Studies, 25 (4): 1207-1254.

Goyenko, R., Subrahmanyam, A., and Uhkov, A. (2011). The Term Structure of Bond Market Liquidity and Its Implications for Expected Bond Returns. Journal of Financial and Quantitative Analysis, 46 (1): 111-139.

Gromb, D. and Vayanos, D. (2002). Equilibrium and Welfare in Markets with Financially Constrained Arbitrageurs. Journal of Financial Economics, 66 (2): 361-407.

Gürkaynak, R. S., Sack, B., and Wright, J. H. (2010). The TIPS Yield Curve and Inflation Compensation. American Economic Journal: Macroeconomics, 2 (1): 70-92. 
Haubrich, J., Pennacchi, G., and Ritchken, P. (2012). Inflation Expectations, Real Rates, and Risk Premiums: Evidence from Inflation Swaps. Review of Financial Studies, 25 (5): 1588-1629.

Houweling, P., Mentink, P., and Vorst, T. (2005). Comparing Possible Proxies of Corporate Bond Liquidity. Journal of Banking \&f Finance, 29 (6): 1331-1358.

Jordan, B., Jorgensen, R., and Kuipers, D. (2000). The Relative Pricing of U.S. Treasury STRIPS. Journal of Financial Economics, 56 (1): 89-123.

Kerkhof, J. (2005). Inflation Derivatives Explained. Fixed Income Quantitative Research, Lehman Brothers, 1-80.

Korajczyk, R. A. and Sadka, R. (2008). Pricing the Commonality Across Alternative Measures of Liquidity. Journal of Financial Economics, 87 (1): 45-72.

Krishnamurthy, A. (2002). The Bond/Old Bond Spread. Journal of Financial Economics, 66 (2): 463-506.

Krishnamurthy, A. and Vissing-Jorgensen, A. (2010). The Aggregate Demand for Treasury Debt. Working paper, Northwestern University.

Longstaff, F. A. (2004). The Flight to Liquidity Premium in U.S. Treasury Bond Prices. Journal of Business, 77 (3): 511-526.

Mitchell, M., Pedersen, L. H., and Pulvino, T. (2007). Slow Moving Capital. American Economic Review P\&YP, 97 (2): 215-220.

Pastor, L. and Stambaugh, R. F. (2003). Liquidity Risk and Expected Stock Returns. Journal of Political Economy, 111 (3): 642-685.

Petersen, M. A. (2009). Estimating Standard Errors in Finance Panel Data Sets: Comparing Approaches. Review of Financial Studies, 22 (1): 435-480.

Pflueger, C. E. and Viceira, L. M. (2011). Inflation-Indexed Bonds and the Expectations Hypothesis. Annual Review of Financial Economics, 3 (1): 139-158.

Pflueger, C. E. and Viceira, L. M. (2015). Return Predictability in the Treasury Market: Real Rates, Inflation, and Liquidity. In Veronesi, P., editor, Handbook of Fixed-Income Securities. Wiley and Sons, New Jersey, New Jersey.

Roll, R. (1984). A Simple Implicit Measure of the Bid-Ask Spread in an Efficient Market. Journal of Finance, 39 (4): 1127-1139.

Ruenzi, S., Ungeheuer, M., and Weigert, F. (2016). Extreme Downside Liquidity Risk. Working paper 2013/26, University of St. Gallen.

Schwarz, K. (2015). Mind the Gap: Disentangling Credit and Liquidity Risks in Spreads. Working paper. 
Simon, Z. (2015). Not Risk Free: The Relative Pricing of Euro Area Inflation-Indexed and Nominal Bonds. Discussion paper 11/2015-074, Netspar.

Tang, D. and Yan, H. (2007). Liquidity and Credit Default Swap Spreads. Working paper, University of Hong Kong.

Vayanos, D. (2004). Flight to Quality, Flight to Liquidity, and the Pricing of Risk. Working paper, London School of Economics. 
Table 1

Descriptive statistics

The table presents descriptive statistics for variables used in the two-stage estimation. Panel A presents variables of inflation swaps, whereas Panel B and C show those for TIPS and nominal Treasuries, respectively. Swap yields are the percentage quoted rates of a swap contracts, whereas yield volatility is defined as the difference between the standard deviation of individual issues and the cross-sectional average standard deviation of quoted yields. The Roll measure is the scaled autocovariance of inflation swap returns, while the proportion of zero returns is measured as the percentage of days with zero returns over a month. Age and time-to-maturity are defined relative to the issue and maturity dates of bonds. The on-the-run dummy is an indicator variable, that equals 1 if the given issue is the latest of its tenor and zero otherwise. ILLIQ is the monthly average ratio of weekly absolute bond market returns over weekly aggregate trading volume. Yields, volatilities, the Roll and the zero returns measures are in percentages, age and time-to-maturity are measured in years. The data correspond to the sample period between July 2004 and December 2011.

\section{Panel A: Descriptive statistics of inflation swap markets}

\begin{tabular}{|c|c|c|c|c|c|c|}
\hline & Mean & St. Dev. & Min & p25 & p75 & $\operatorname{Max}$ \\
\hline Swap yield & 2.47 & 0.71 & -3.83 & 2.33 & 2.87 & 3.41 \\
\hline Yield volatility & 0 & 0.06 & -0.35 & -0.02 & 0.01 & 1.14 \\
\hline Roll measure & 0.25 & 0.43 & 0 & 0 & 0.31 & 5.58 \\
\hline Proportion of zeros & 5.82 & 13.63 & 0 & 0 & 5 & 100 \\
\hline Average Roll m. & 0.25 & 0.24 & 0 & 0.09 & 0.36 & 1.92 \\
\hline \multicolumn{7}{|c|}{ Panel B: Descriptive statistics of TIPS } \\
\hline & Mean & St. Dev. & Min & $\mathrm{p} 25$ & $\mathrm{p} 75$ & Max \\
\hline TIPS yield & 0.07 & 1.67 & -3.02 & -1.26 & 1.34 & 7.47 \\
\hline Age & 4.38 & 3 & 0 & 1.95 & 6.54 & 13.72 \\
\hline Time-to-maturity & 9.12 & 6.93 & 16 & 3.80 & 15.48 & 27.73 \\
\hline Issued amount & 23.50 & 0.39 & 22.34 & 23.43 & 23.72 & 24.06 \\
\hline Yield volatility & 0 & 0.07 & -0.42 & -0.02 & 0.01 & 1.08 \\
\hline On-the-run & 0.13 & 0.33 & 0 & 0 & 0 & 1 \\
\hline ILLIQ & 1.51 & 0.45 & 0.87 & 1.19 & 1.77 & 2.91 \\
\hline \multicolumn{7}{|c|}{ Panel C: Descriptive statistics of nominal Treasuries } \\
\hline & Mean & St. Dev. & Min & $\mathrm{p} 25$ & $\mathrm{p} 75$ & $\operatorname{Max}$ \\
\hline Nominal yield & 1.58 & 1.31 & -0.67 & 0.46 & 2.59 & 4.51 \\
\hline Age & 5.86 & 3.98 & 0 & 2.50 & 8.63 & 16.88 \\
\hline Time-to-maturity & 9.48 & 7.10 & 0.13 & 3.90 & 16.56 & 26.56 \\
\hline Issued amount & 23.77 & 0.42 & 23.07 & 23.43 & 24.06 & 24.92 \\
\hline Yield volatility & 0 & 0.03 & -0.17 & -0.01 & 0.01 & 0.23 \\
\hline On-the-run & 0.05 & 0.21 & 0 & 0 & 0 & 1 \\
\hline ILLIQ & 2.38 & 0.55 & 1.55 & 2.01 & 2.56 & 5.22 \\
\hline
\end{tabular}


Table 2

\section{Beta estimates}

The table presents the distribution of risk sensitivities estimated from the time-series regression of asset returns on market and non-traded illiquidity factors. Panel A presents variables of inflation swaps, whereas Panel B and C show those for TIPS and nominal Treasuries, respectively. We estimate market and illiquidity betas for 15 swaps, 31 TIPS and 32 nominal Treasury issues in the sample that spans the period between July 2004 and December 2011.

\begin{tabular}{|c|c|c|c|c|c|c|}
\hline \multicolumn{7}{|c|}{ Panel A: Inflation swap market } \\
\hline & Mean & St. Dev. & Min & $\mathrm{p} 25$ & $\mathrm{p} 75$ & $\operatorname{Max}$ \\
\hline Segmented market $\beta$ & 1 & 0.57 & 0.22 & 0.57 & 1.40 & 2.18 \\
\hline Segmented illiquidity $\beta$ & 0 & 1.50 & -4.14 & -0.29 & 0.68 & 2.95 \\
\hline Integrated market $\beta$ & 0.02 & 0.26 & -0.43 & -0.27 & 0.24 & 0.43 \\
\hline Integrated illiquidity $\beta$ & -4.09 & 3.09 & -12.78 & -5.59 & -2.37 & -0.30 \\
\hline \multicolumn{7}{|l|}{ Panel B: TIPS market } \\
\hline & Mean & St. Dev. & Min & $\mathrm{p} 25$ & p75 & $\operatorname{Max}$ \\
\hline Segmented market $\beta$ & 0.96 & 0.45 & 0.29 & 0.53 & 1.42 & 1.92 \\
\hline Segmented illiquidity $\beta$ & 0.01 & 0.39 & -0.90 & -0.26 & 0.35 & 0.47 \\
\hline Integrated market $\beta$ & 0.99 & 0.59 & 0.16 & 0.46 & 1.61 & 2.04 \\
\hline Integrated illiquidity $\beta$ & 0.46 & 0.44 & -0.68 & 0.06 & 0.73 & 1.17 \\
\hline \multicolumn{7}{|c|}{ Panel C: Nominal Treasury market } \\
\hline & Mean & St. Dev. & Min & $\mathrm{p} 25$ & $\mathrm{p} 75$ & $\operatorname{Max}$ \\
\hline Segmented market $\beta$ & 0.96 & 0.57 & 0.17 & 0.39 & 1.66 & 1.90 \\
\hline Segmented illiquidity $\beta$ & -0.07 & 0.25 & -0.67 & -0.16 & 0.10 & 0.51 \\
\hline Integrated market $\beta$ & 0.95 & 0.56 & 0.19 & 0.37 & 1.66 & 1.85 \\
\hline Integrated illiquidity $\beta$ & -0.37 & 0.37 & -1.21 & -0.65 & -0.12 & 0.50 \\
\hline
\end{tabular}


Table 3

\section{Monthly swap yields and illiquidity - Market segmentation}

The table reports estimates for the second step (Equation 4) of the Fama-MacBeth procedure under the assumption of markets being segmented. The dependent variable is the inflation swap yield. Market and illiquidity betas are loadings on the market and non-traded illiquidity factors. The Roll measure is calculated as the scaled autocovariance of returns for the case when it is strictly negative otherwise the measure is truncated at zero. The proportion of zero returns is measured as the percentage of days with zero returns over a month, whereas (lagged) yield volatility is defined as the difference between the standard deviations of individual issues and the cross-sectional average standard deviation of quoted yields, where the average is take over the different maturities for a given month. The economic impact is captured by the interquartile spread, which is defined as the product of the coefficient and the difference between the betas that correspond to the first and third quartile in the cross-sectional distribution of betas. Displayed coefficients are average figures from monthly repeated cross-sectional regressions, where errors take into account the averaging and include a 12-lag Newey-West correction. The sample period is July 2004 until December 2011. t-statistics are given in parentheses and *, **, and *** denote significance at the $10 \%, 5 \%$, and $1 \%$ level.

\begin{tabular}{|c|c|c|c|c|c|c|}
\hline & Benchmark & $(2)$ & (3) & (4) & $(5)$ & (6) \\
\hline Market beta & $\begin{array}{c}0.5338 \\
(3.91)^{* * *}\end{array}$ & $\begin{array}{c}0.4269 \\
(4.38)^{* * *}\end{array}$ & $\begin{array}{c}0.5796 \\
(3.25)^{* * *}\end{array}$ & $\begin{array}{c}0.5330 \\
(3.77)^{* * *}\end{array}$ & $\begin{array}{c}0.4518 \\
(3.93)^{* * *}\end{array}$ & $\begin{array}{c}0.4466 \\
(3.80)^{* * *}\end{array}$ \\
\hline Illiquidity beta & $\begin{array}{l}0.0171 \\
(2.18)^{* *}\end{array}$ & $\begin{array}{l}0.0092 \\
(2.21)^{* *}\end{array}$ & $\begin{array}{c}0.0048 \\
(1.06)\end{array}$ & $\begin{array}{l}0.0226 \\
(1.91)^{*}\end{array}$ & $\begin{array}{l}0.0056 \\
(1.67)^{*}\end{array}$ & $\begin{array}{l}0.0106 \\
(1.96)^{*}\end{array}$ \\
\hline Yield volatility $_{t-1}$ & & $\begin{array}{l}-2.0809 \\
(1.78)^{*}\end{array}$ & & & $\begin{array}{c}-1.7160 \\
(-1.62)\end{array}$ & $\begin{array}{c}-1.5542 \\
(-1.64)\end{array}$ \\
\hline Roll measure & & & $\begin{array}{l}-0.1647 \\
(-0.86)\end{array}$ & & $\begin{array}{c}0.0516 \\
(0.65)\end{array}$ & $\begin{array}{c}0.0588 \\
(0.79)\end{array}$ \\
\hline Proportion of zero returns & & & & $\begin{array}{c}-0.0158 \\
(-1.46)\end{array}$ & & $\begin{array}{l}-0.0091 \\
(1.67)^{*}\end{array}$ \\
\hline Intercept & $\begin{array}{l}1.9402 \\
(6.88)^{* * *}\end{array}$ & $\begin{array}{c}2.0428 \\
(8.63)^{* * *}\end{array}$ & $\begin{array}{c}1.9189 \\
(6.57)^{* * *}\end{array}$ & $\begin{array}{c}1.9602 \\
(7.03)^{* * *}\end{array}$ & $\begin{array}{c}2.0200 \\
(8.18)^{* * *}\end{array}$ & $\begin{array}{c}2.0401 \\
(8.27)^{* * *}\end{array}$ \\
\hline $\begin{array}{l}\text { Adj. } R^{2} \\
\text { Number of obs. }\end{array}$ & $\begin{array}{c}0.67 \\
1,350\end{array}$ & $\begin{array}{c}0.85 \\
1,335\end{array}$ & $\begin{array}{c}0.71 \\
1,350\end{array}$ & $\begin{array}{c}0.68 \\
1,350\end{array}$ & $\begin{array}{c}0.86 \\
1,335\end{array}$ & $\begin{array}{c}0.87 \\
1,335\end{array}$ \\
\hline $\begin{array}{l}\text { Impact of market risk } \\
\text { Impact of liquidity risk }\end{array}$ & $\begin{array}{l}0.4392 \\
0.0165\end{array}$ & $\begin{array}{l}0.3512 \\
0.0089\end{array}$ & $\begin{array}{l}0.4768 \\
0.0046\end{array}$ & $\begin{array}{l}0.4385 \\
0.0218\end{array}$ & $\begin{array}{l}0.3717 \\
0.0053\end{array}$ & $\begin{array}{l}0.3674 \\
0.0102\end{array}$ \\
\hline
\end{tabular}


Table 4

Monthly swap yields and illiquidity Market integration

The table reports estimates for the second step (Equation 4) of the Fama-MacBeth procedure under the assumption of integrated markets. The dependent variable is the inflation swap yield. Market and illiquidity betas are estimated as loadings on the market and non-traded illiquidity factors. The Roll measure is calculated as the scaled autocovariance of returns for the case when it is strictly negative otherwise the measure is truncated at zero. The proportion of zero returns is measured as the percentage of days with zero returns over a month, whereas (lagged) yield volatility is defined as the difference between the standard deviations of individual issues and the cross-sectional average standard deviation of quoted yields, where the average is take over the different maturities for a given month. The economic impact is captured by the interquartile spread, which is defined as the product of the coefficient and the difference between the betas that correspond to the first and third quartile in the cross-sectional distribution of betas. Displayed coefficients are average figures from monthly repeated cross-sectional regressions where errors take into account the averaging and include a 12-lag Newey-West correction. The sample period is July 2004 until December 2011. t-statistics are given in parentheses and *, **, and $* * *$ denote significance at the $10 \%, 5 \%$, and $1 \%$ level.

(1)

(2)

(3)

(4)

(5)

(6)

Market beta

Illiquidity beta

Yield volatility $t-1$

\begin{tabular}{cc}
\hline 0.4531 & 0.2626 \\
$(2.44)^{* *}$ & $(2.38)^{* *}$ \\
-0.0662 & -0.0462 \\
$(5.03)^{* * *}$ & $(6.25)^{* * *}$ \\
& -3.2833 \\
& $(2.65)^{* * *}$
\end{tabular}

Roll measure

$(2.65)^{* * *}$

0.4130

$(2.38)^{* *}$

0.4729

$(2.36)^{* *}$

$-0.0607$

$(4.23)^{* * *}$

$(5.34) * * *$

0.2508

$(2.40)^{* *}$

$-0.0402$

-0.0402
$(5.39) * * *$

$-3.3298$

$(2.60)^{* *}$

$-0.1200$

0.3478

$(-0.64)$

(1.22)

0.2674

$(2.33)^{* *}$

$-0.0353$

Proportion of zero returns

Intercept

2.1947

2.2759

2.1716

$-0.0051$

$(-0.62)$

$(10.85)^{* * *}$

$(13.04)^{* * *}$

$(10.41)^{* * *}$

2.2202

$(12.03)^{* * *}$

2.2578

$(12.52)^{* * *}$

$-2.8924$

-2.8924
$(2.82)^{* * *}$

0.3463

(1.20)

$-0.0084$

$(-1.40)$

\begin{tabular}{cccccc}
\hline 0.59 & 0.75 & 0.62 & 0.61 & 0.78 & 0.80 \\
1,350 & 1,335 & 1,350 & 1,350 & 1,335 & 1,335 \\
\hline 0.2330 & 0.1351 & 0.2124 & 0.2432 & 0.1290 & 0.1375 \\
-0.0341 & -0.0238 & -0.0319 & -0.0312 & -0.0207 & -0.0182 \\
\hline
\end{tabular}

Adj. R ${ }^{2}$

Number of obs.

$-0.0341$

$-0.0238$

$-0.0319$

$-0.0207$ 


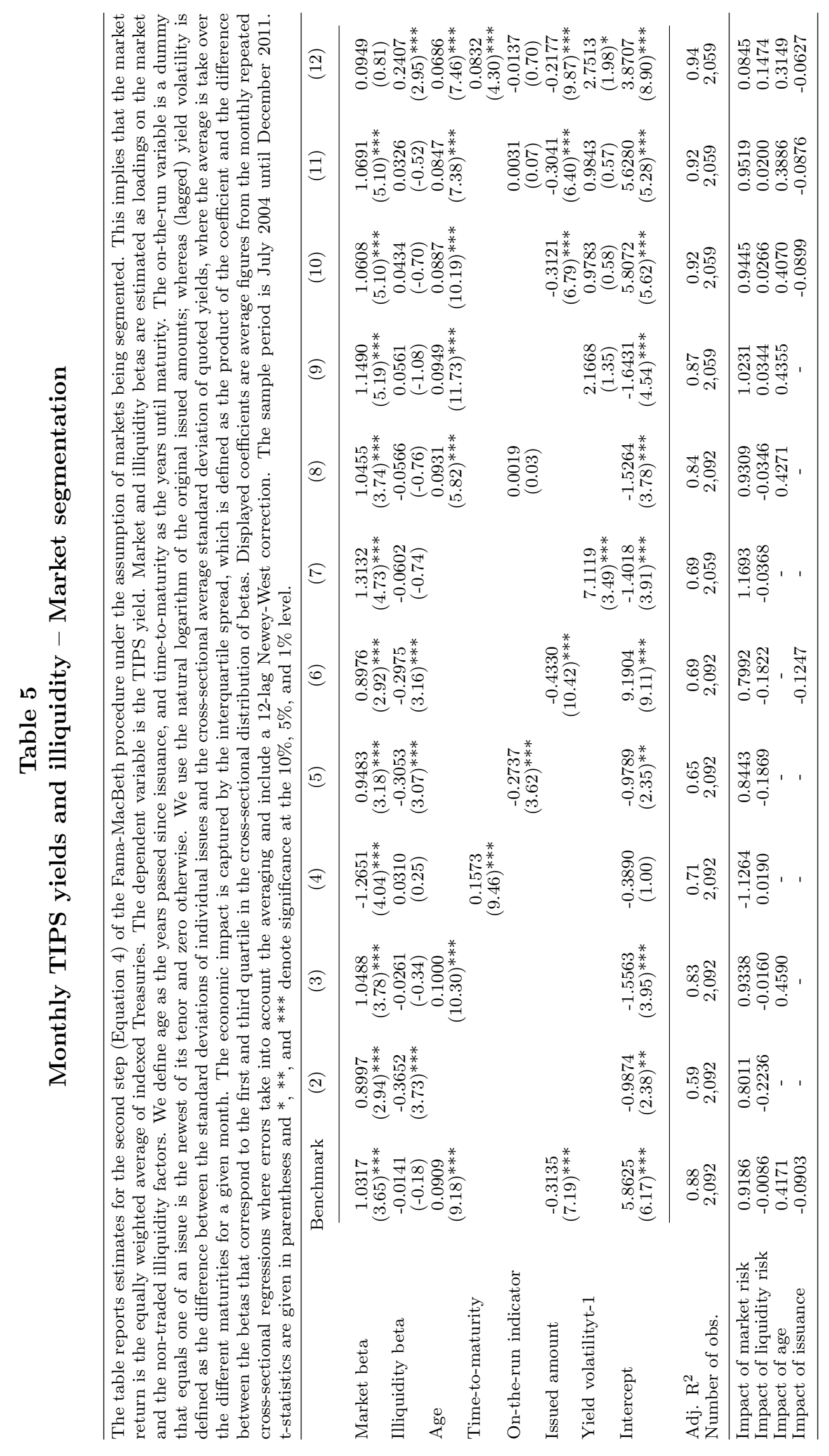




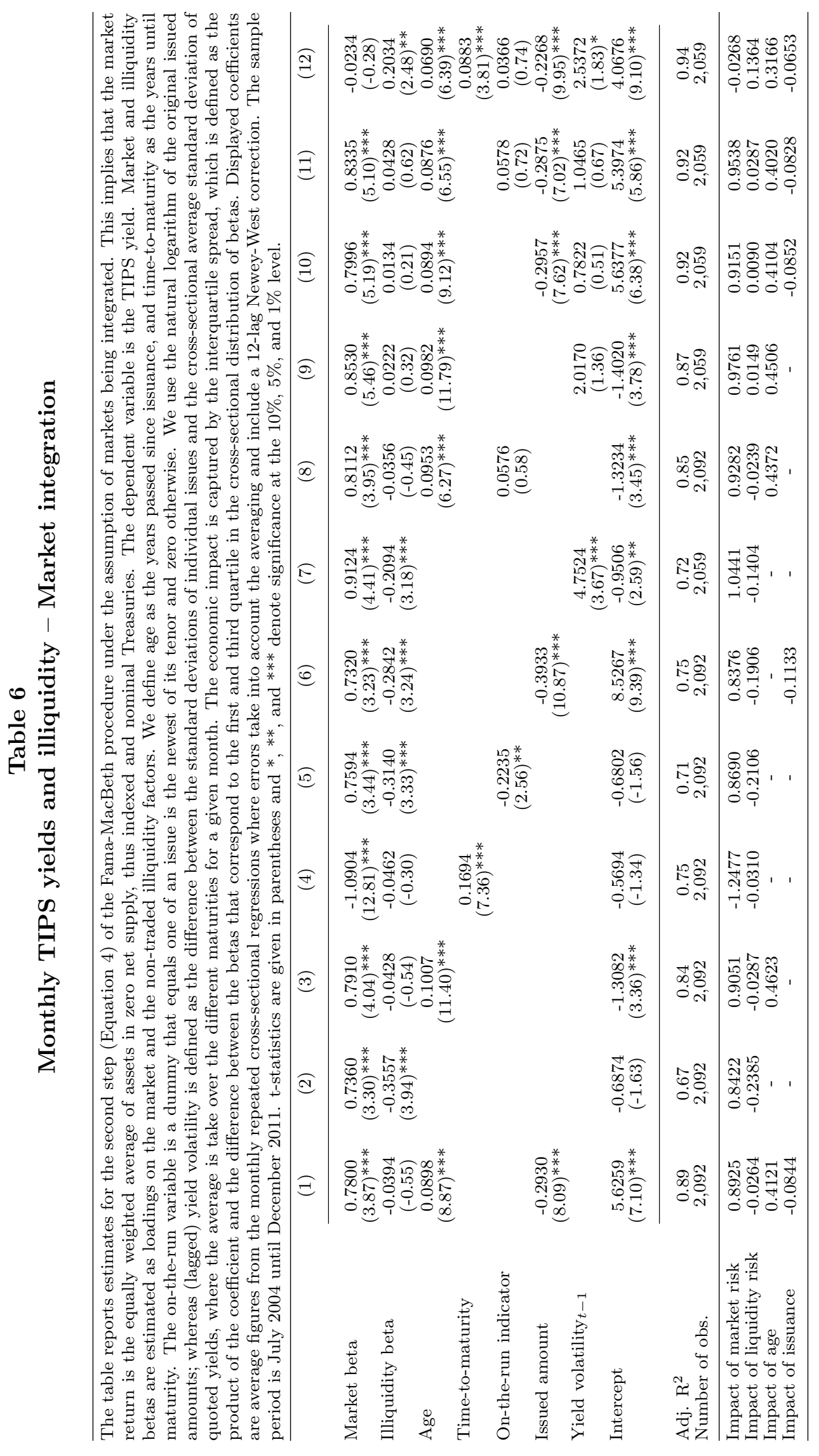




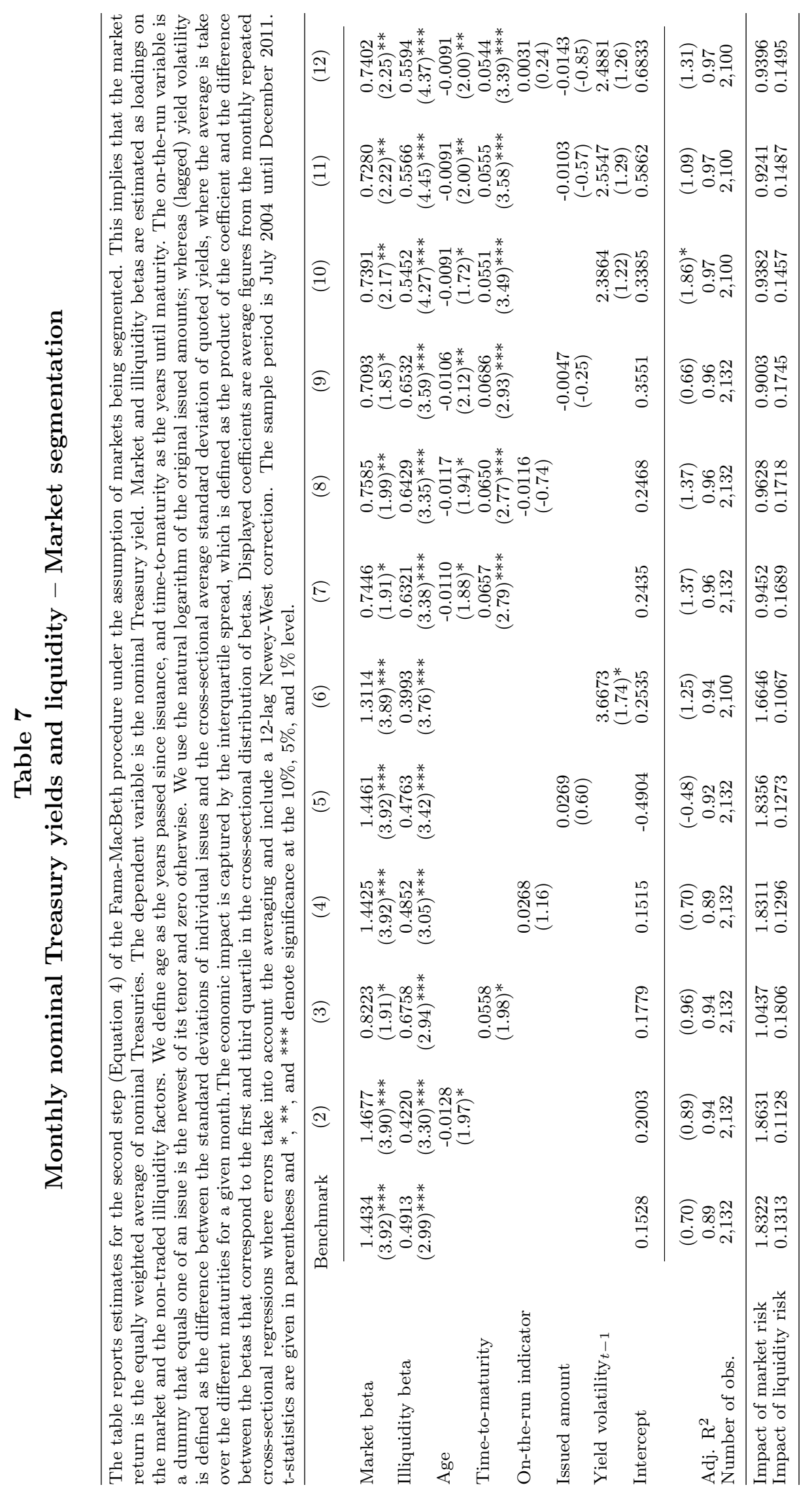




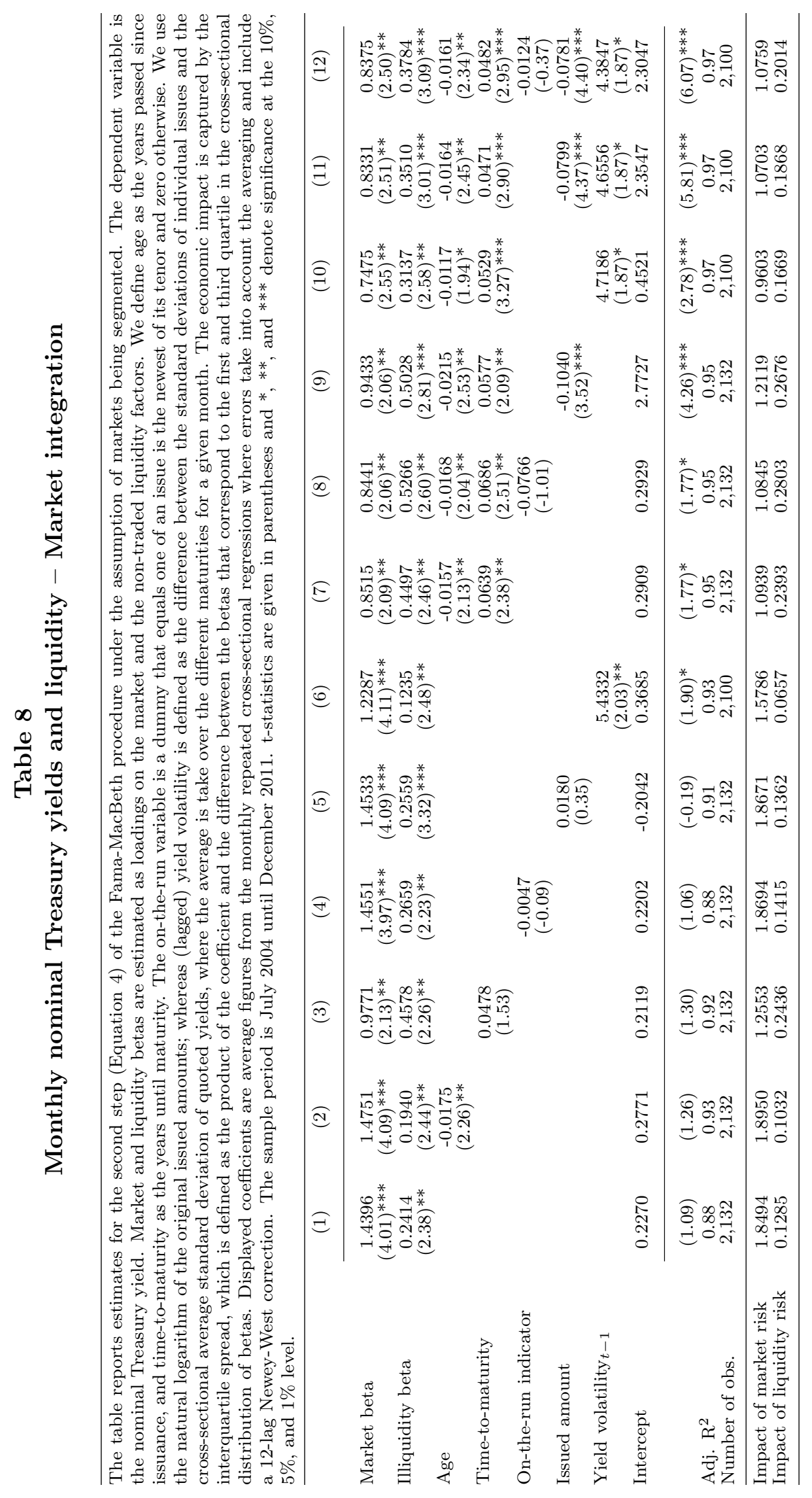


Table 9

\section{Liquidity regimes}

The table reports estimates for the second step (Equation 4) of the Fama-MacBeth procedure under the assumption of markets being segmented, but considering months of increasing and decreasing liquidity separately. The dependent variable is either the bond yields or the swap. Market and liquidity betas are estimated as loadings on the market and the non-traded liquidity factors. We define age as years passed since issuance, and time-to-maturity as the years until maturity. To proxy for size, we use the natural logarithm of the original issued amounts. Displayed coefficients are average figures from the monthly repeated cross-sectional regressions where errors take into account the averaging. The sample period is July 2004 until December 2011. T-statistics are given in parentheses and $*, * *$, and $* * *$ denote significance at the $10 \%, 5 \%$, and $1 \%$ level.

Panel A: Monthly TIPS yields

\begin{tabular}{|c|c|c|c|}
\hline & Benchmark & Increasing illiquidity & Decreasing illiquidity \\
\hline Segmented market beta & $\begin{array}{c}0.932 \\
(10.08)^{* * *}\end{array}$ & $\begin{array}{c}0.892 \\
(6.33)^{* * *}\end{array}$ & $\begin{array}{c}0.975 \\
(8.22)^{* * *}\end{array}$ \\
\hline Segmented illiq. beta & $\begin{array}{r}-0.032 \\
(0.88)\end{array}$ & $\begin{array}{r}-0.048 \\
(0.85)\end{array}$ & $\begin{array}{r}-0.013 \\
(0.31)\end{array}$ \\
\hline Age & $\begin{array}{c}0.088 \\
(23.07)^{* * *}\end{array}$ & $\begin{array}{c}0.090 \\
(14.70)^{* * *}\end{array}$ & $\begin{array}{c}0.085 \\
(19.71)^{* * *}\end{array}$ \\
\hline Size & $\begin{array}{c}-0.239 \\
(19.35)^{* * *}\end{array}$ & $\begin{array}{c}-0.247 \\
(13.91)^{* * *}\end{array}$ & $\begin{array}{c}-0.230 \\
(13.39)^{* * *}\end{array}$ \\
\hline Constant & $\begin{array}{c}4.241 \\
(13.01)^{* * *}\end{array}$ & $\begin{array}{c}4.605 \\
(9.88)^{* * *}\end{array}$ & $\begin{array}{c}3.844 \\
(8.50)^{* * *}\end{array}$ \\
\hline $\begin{array}{l}\mathrm{R}^{2} \\
\mathrm{~N}\end{array}$ & $\begin{array}{c}0.87 \\
2,216\end{array}$ & $\begin{array}{c}0.86 \\
1,155\end{array}$ & $\begin{array}{c}0.88 \\
1,061\end{array}$ \\
\hline \multicolumn{4}{|c|}{ Panel B: Monthly nominal Treasury yields } \\
\hline & Benchmark & Increasing illiquidity & Decreasing illiquidity \\
\hline Segmented market beta & $\begin{array}{c}1.372 \\
(13.41)^{* * *}\end{array}$ & $\begin{array}{c}1.421 \\
(10.17)^{* * *}\end{array}$ & $\begin{array}{c}1.311 \\
(8.66)^{* * *}\end{array}$ \\
\hline Segmented illiq. beta & $\begin{array}{c}0.524 \\
(8.05)^{* * *}\end{array}$ & $\begin{array}{c}0.537 \\
(5.96)^{* * *}\end{array}$ & $\begin{array}{c}0.508 \\
(5.35)^{* * *}\end{array}$ \\
\hline Constant & $\begin{array}{c}0.230 \\
(3.49)^{* * *}\end{array}$ & $\begin{array}{c}0.244 \\
(2.56)^{* *}\end{array}$ & $\begin{array}{c}0.214 \\
(2.37)^{* *}\end{array}$ \\
\hline $\mathrm{R}^{2}$ & 0.89 & 0.89 & 0.89 \\
\hline $\mathrm{N}$ & 2,252 & 1,255 & 997 \\
\hline \multicolumn{4}{|c|}{ Panel C: Monthly inflation swap rates } \\
\hline & Benchmark & Increasing illiquidity & Decreasing illiquidity \\
\hline Segmented market beta & $\begin{array}{c}0.534 \\
(10.46)^{* * *}\end{array}$ & $\begin{array}{c}0.555 \\
(7.12)^{* * *}\end{array}$ & $\begin{array}{c}0.511 \\
(7.76)^{* * *}\end{array}$ \\
\hline Segmented illiq. beta & $\begin{array}{c}0.017 \\
(6.41)^{* * *}\end{array}$ & $\begin{array}{c}0.018 \\
(4.37)^{* * *}\end{array}$ & $\begin{array}{c}0.017 \\
(4.71)^{* * *}\end{array}$ \\
\hline Constant & $\begin{array}{c}1.940 \\
(18.54)^{* * *}\end{array}$ & $\begin{array}{c}1.917 \\
(11.79)^{* * *}\end{array}$ & $\begin{array}{c}1.965 \\
(14.88)^{* * *}\end{array}$ \\
\hline $\mathrm{R}^{2}$ & 0.72 & 0.71 & 0.72 \\
\hline $\mathrm{N}$ & 1,350 & 690 & 660 \\
\hline
\end{tabular}




\section{Table 10}

\section{The mispricing}

The table presents descriptive statistics of the replicated trading strategy of Fleckenstein et al. (2014). In the strategy we compare the prices of a nominal Treasury issue to its replicating portfolio that consist of a maturity matched TIPS issue, inflation swap contracts and small positions in STRIPS. Panel A presents the results of the replication for our sample, alongside with the two types of liquidity corrections applied to this strategy. The correction is based on adjusting yields with estimated liquidity premiums both under the assumption of the three markets being segmented and integrated. The value of the liquidity adjusted swap positins follow Equation 9. Panel B exhibits the difference between the original strategy and the adjusted versions, where the difference is taken between the FLL mispricing and the corrected series. The data correspond to 26 bond pairs and for the period between July 2004 and December 2011.

\begin{tabular}{|c|c|c|c|c|c|c|}
\hline \multicolumn{7}{|l|}{ Panel A: Mispricing and corrections } \\
\hline & Mean & St. Dev. & Min & p25 & p75 & $\operatorname{Max}$ \\
\hline FLL mispricing & 3.983 & 1.647 & 1.470 & 3.167 & 4.247 & 12.444 \\
\hline Segmentation-corrected price differential & 1.170 & 1.575 & -1.029 & 0.294 & 1.395 & 9.167 \\
\hline Integration-corrected price differential & 2.427 & 1.740 & -0.255 & 1.398 & 2.742 & 11.081 \\
\hline \multicolumn{7}{|c|}{ Panel B: The effect of liquidity correction } \\
\hline & Mean & St. Dev. & Min & $\mathrm{p} 25$ & p75 & $\operatorname{Max}$ \\
\hline Difference in segmentation & 2.807 & 0.216 & 2.292 & 2.702 & 2.948 & 3.385 \\
\hline Difference in integration & 1.546 & 0.326 & 0.945 & 1.302 & 1.723 & 2.761 \\
\hline
\end{tabular}




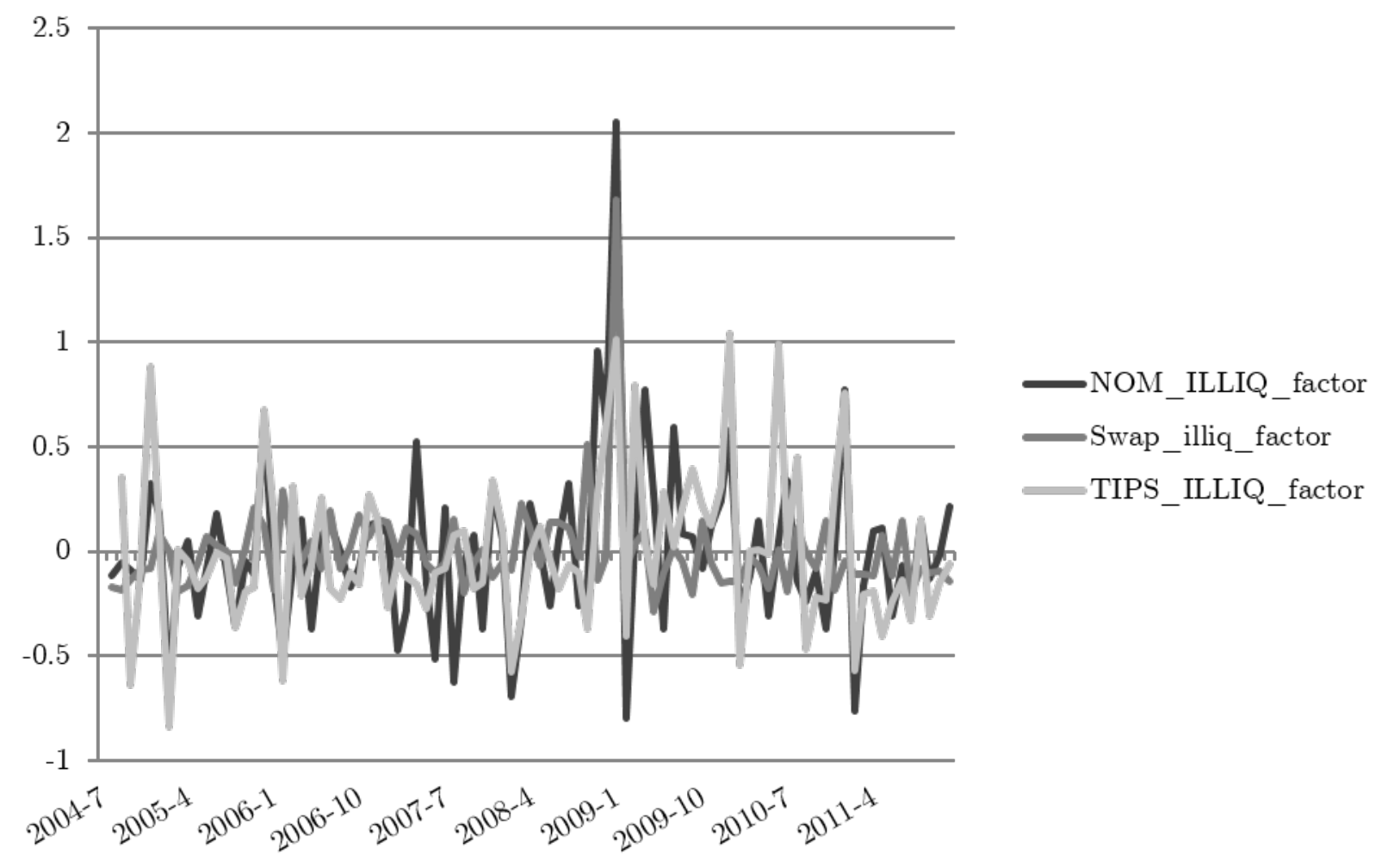

Figure 1 Illiquidity factors

The figure depicts the time evolution of the non-traded illiquidity factors. They are residuals from autoregressive processes: $\operatorname{AR}(3)$ for ILLIQ measures of nominal and indexed bonds, and $\operatorname{AR}(1)$ for the average Roll measure of inflation swaps. 


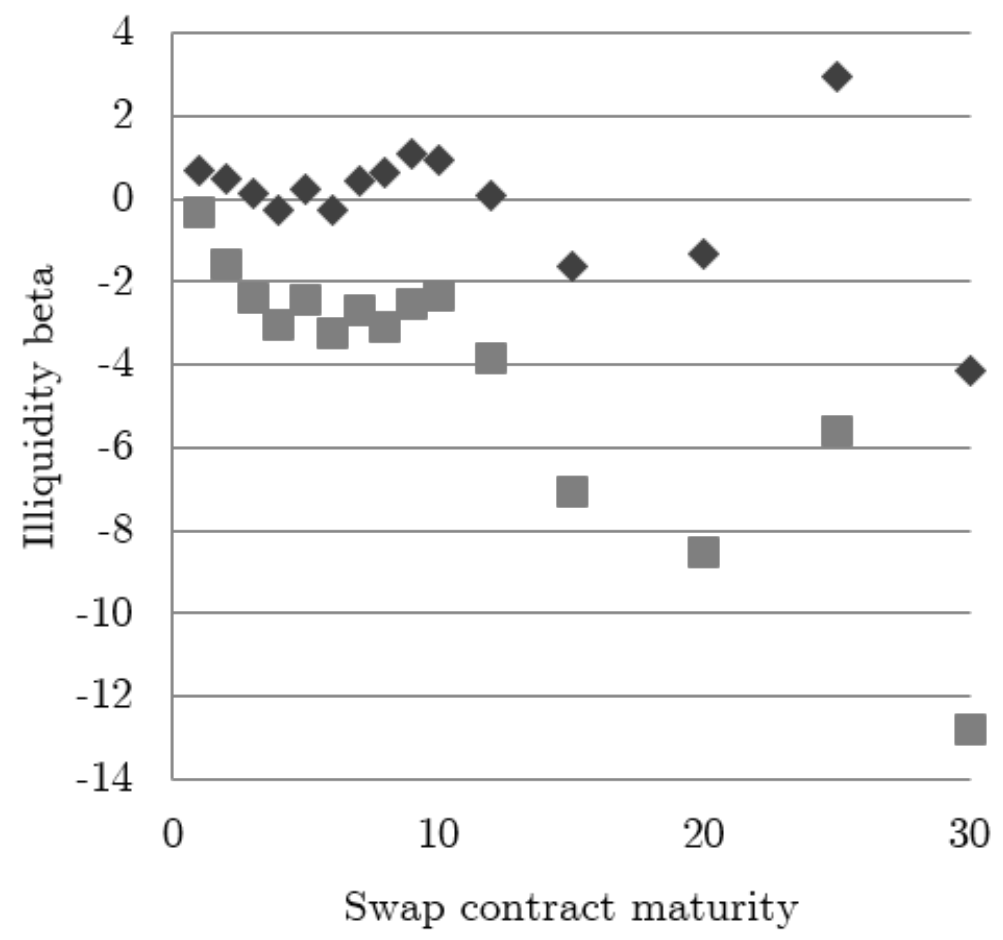

- Swap segmented illiq $\beta$

Swap integrated illiq $\beta$

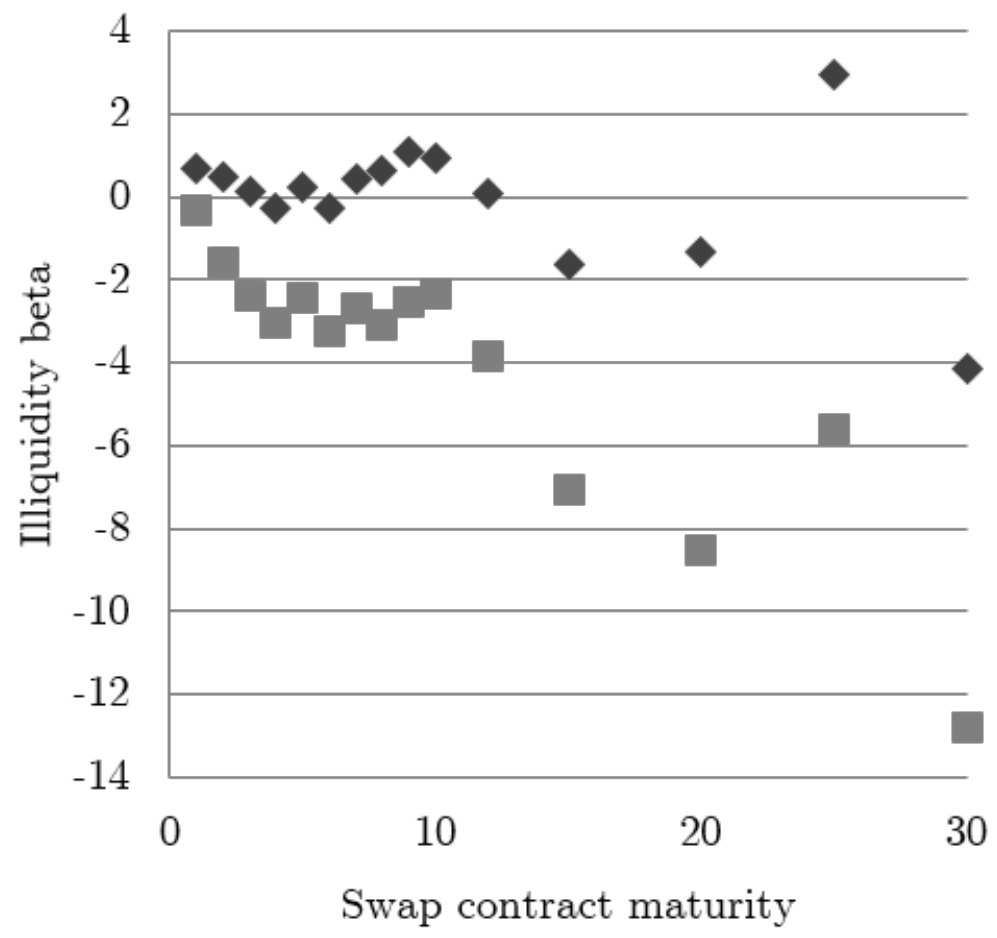

Swap segmented illiq $\beta$

Swap integrated illiq $\beta$

Figure 2 Inflation swap market and illiquidity betas

The scatter plots depict the betas estimated from the time series regressions of inflation swap returns on market and illiquidity factors. The above plot depicts the illiquidity betas, whereas the lower panel presents market betas, both estimated under the assumptions of market segmentation and integration. 


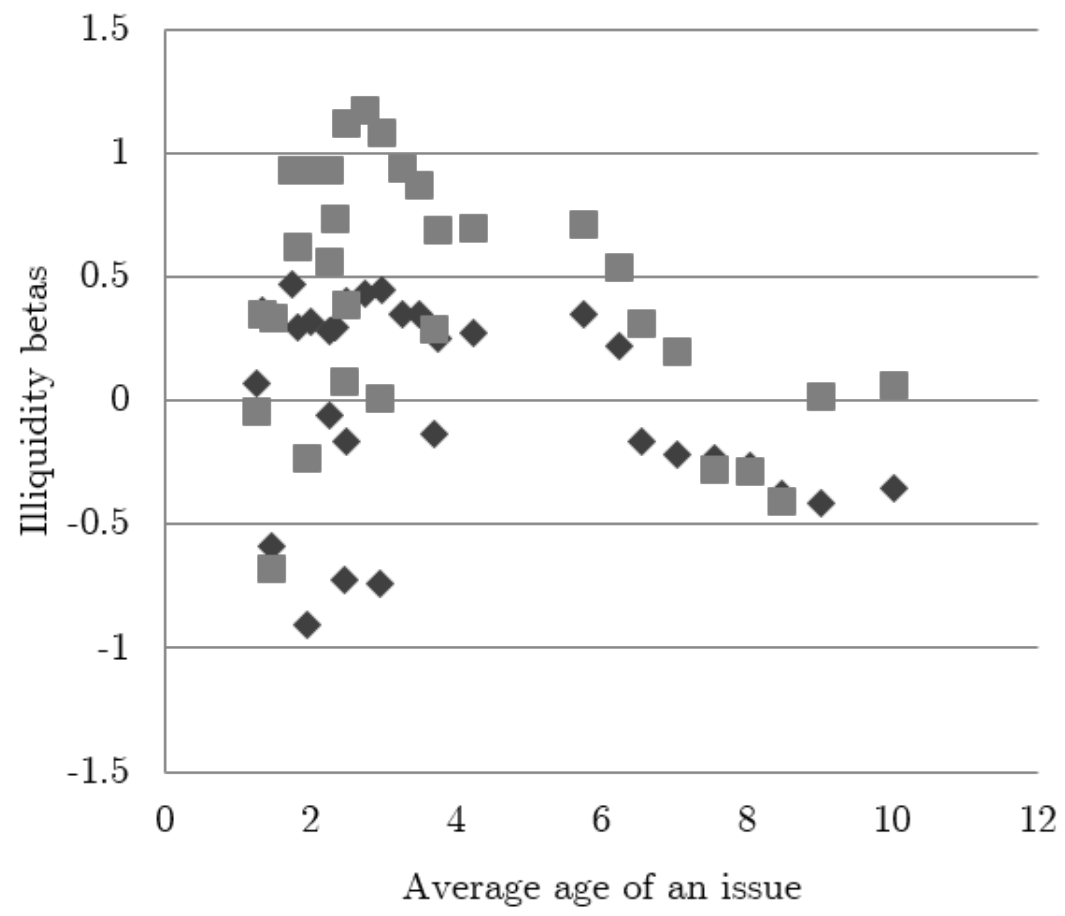

- TIPS segmented illiq $\beta$

TIPS integrated illiq $\beta$

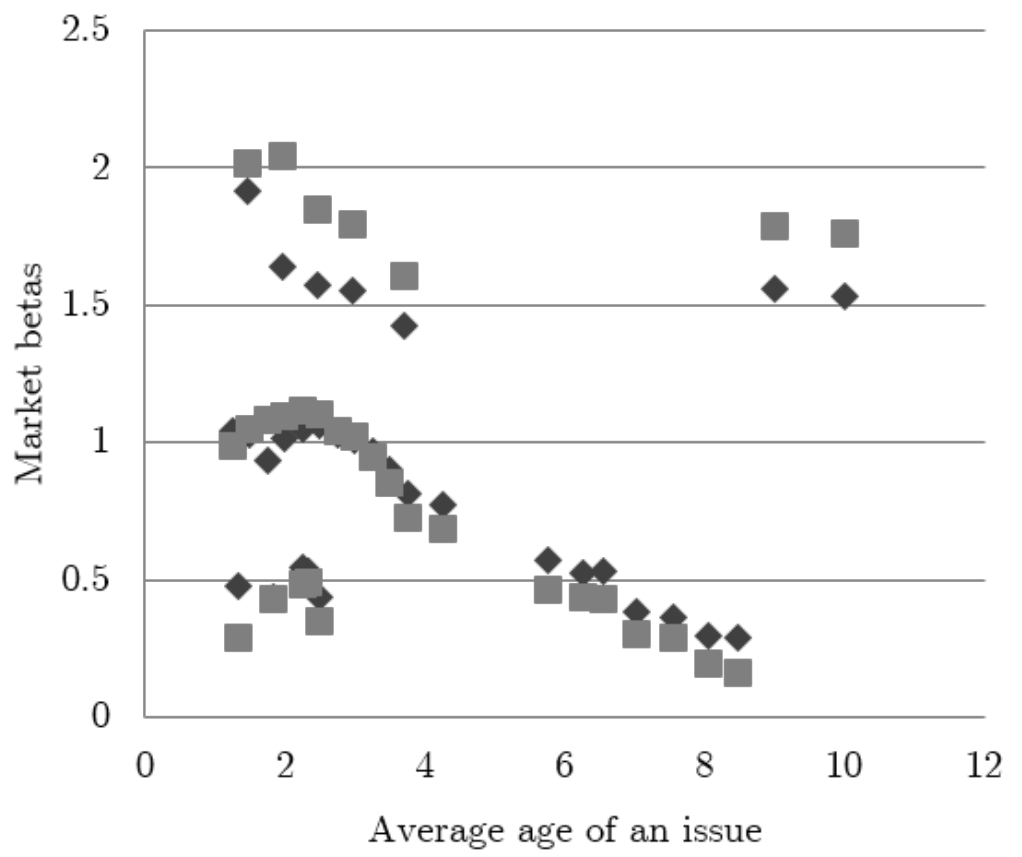

- TIPS segmented market $\beta$

TIPS integrated market $\beta$

Figure 3 TIPS market and illiquidity betas

The scatter plots depict the betas estimated from the time series regressions of TIPS returns on market and illiquidity factors. The above plot depicts the illiquidity betas, whereas the lower panel presents market betas, both estimated under the assumptions of market segmentation and integration. Betas are sorted on average age of bond issues. 

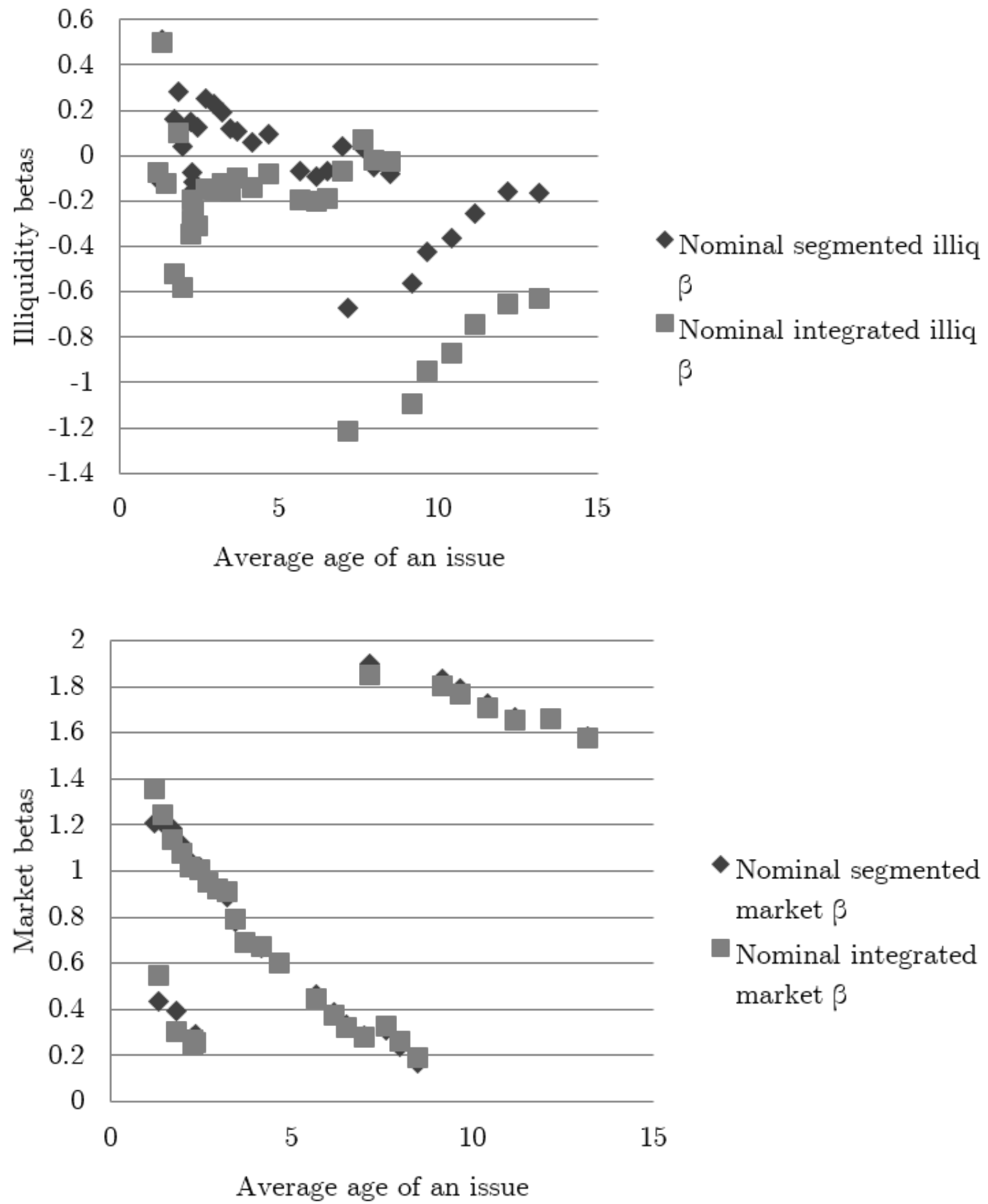

Figure 4 Nominal Treasury market and illiquidity betas

The scatter plots depict the betas estimated from the time series regressions of nominal Treasury returns on market and illiquidity factors. The above plot depicts the illiquidity betas, whereas the lower panel presents market betas, both estimated under the assumptions of market segmentation and integration. Betas are sorted on average age of bond issues. 

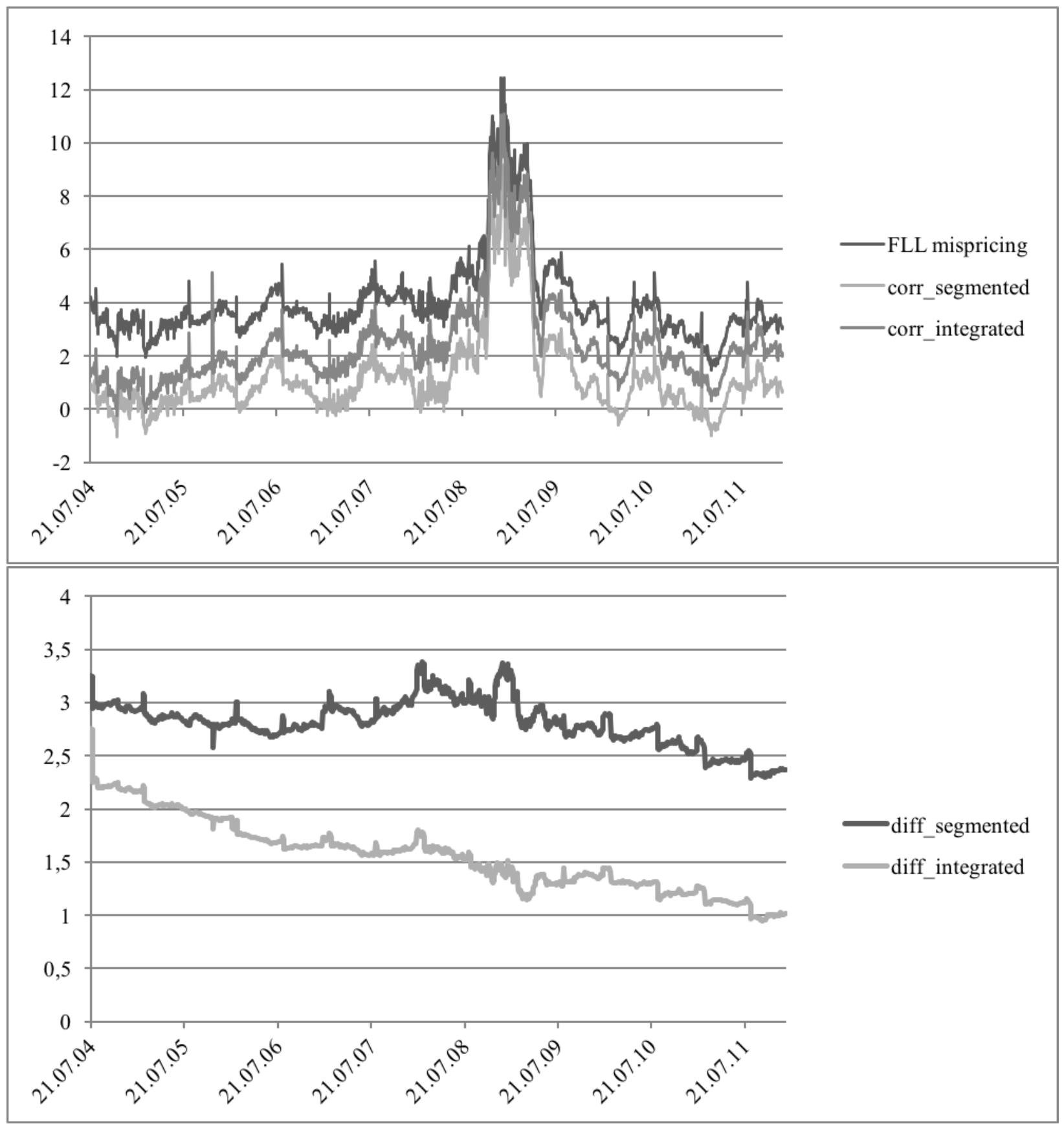

Figure 5 Mispricing and the effect of liquidity correction

The figure depicts the time-series behavior of the equally weighted average mispricing series across 26 maturity matched bond pairs, based on Fleckenstein et al. (2014). The mispricing is the price difference between a nominal Treasury issue and its replicating portfolio that consists of a maturity matched TIPS issue, inflation swap contracts and STRIPS issues. This panel also depicts the liquidity-adjusted series, where corrections based on segmented or integrated markets are applied. In the lower panel, we show the difference between the replicated and the two liquidity-corrected series. 


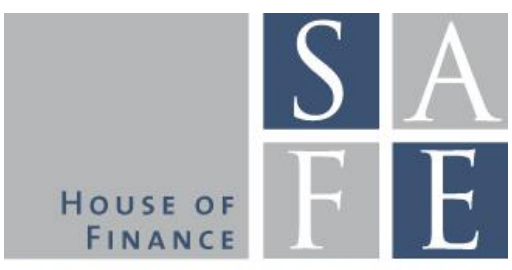

WORKING PAPER SERIES

\section{Recent Issues}

No. 182 Mario Bellia, Loriana Pelizzon, Marti G. Subrahmanyam, Jun Uno, Darya Yuferova

No. 181 Holger Kraft, Farina Weiss

No. 180 Tobias H. Tröger

No. 179 Tobias H. Tröger

No. 178 Matthias Goldmann

No. 177 Michael Donadelli, Marcus Jüppner, Max Riedel, Christian Schlag

No.176 Giuliano Curatola, Ilya Dergunov

No. 175 Reint Gropp, Deyan Radev

No. 174 Reint Gropp, Deyan Radev

No. 173 Merlin Kuate Kamga, Christian Wilde

No. 172 Ahmed Khalifa, Massimiliano Caporin, Michele Costola, Shawkat Hammoudeh
Coming Early to the Party

Consumption-Portfolio Choice with

Preferences for Cash

Why MREL Won't Help Much

Too Complex to Work: A Critical Assessment of the Bail-in Tool under the European Bank Recovery and Resolution Regime

United in Diversity? The Relationship between Monetary Policy and Banking Supervision in the Banking Union

Temperature Shocks and Welfare Costs

International Capital Markets with TimeVarying Preferences

International Banking Conglomerates and the Transmission of Lending Shocks across Borders

Social Centralization, Bank Integration and the Transmission of Lending Shocks

Liquidity Premia in CDS Markets

Systemic Risk for Financial Institutions of Major Petroleum-based Economies: The Role of Oil 